\title{
The MODIS Aerosol Algorithm, Products and Validation
}

\author{
L.A. Remer, Y.J. Kaufman, D. Tanré, S. Mattoo, D.A. Chu, J.V. Martins, R-R. Li, \\ C. Ichoku, R. C. Levy, R.G. Kleidman, T.F. Eck, E. Vermote, B.N. Holben
}

\section{Popular summary.}

Aerosols, tiny solid or liquid particles suspended in the atmosphere, were once only a side note in the Atmospheric Sciences. Today we realize the importance of aerosols in instigating or mitigating climate change, in modifying clouds and large-scale precipitation patterns and in affecting human health. Unlike greenhouse gases, which are well-mixed and long-lasting in the atmosphere, aerosols are temporally and spatially variable with lifetimes of a few days to a few weeks. Their transient natures make aerosols difficult to characterize and their effects on climate, hydrology and health difficult to model. Satellites provide the best means to observe the global aerosol system and narrow the uncertainties associated with aerosol characterization, but the satellite observations must be sufficiently accurate to be useful. The MODerate resolution Imaging Spectroradiometer (MODIS) aboard both NASA's Terra and Aqua satellites provides a unique tool to discern the global impact of aerosols. The products derived from MODIS data include aerosol optical thickness, which is a measure of aerosol amount, as well as products that describe the size of the aerosol particles. The MODIS aerosol retrievals are continuously evaluated against ground-truth of an existing global network of highly accurate instruments (AERONET). The results show an accuracy for the MODIS aerosol products that will sufficiently narrow the uncertainty of global aerosol characterization. Furthermore, the MODIS derivation of aerosol particle size aids in discriminating between man-made aerosol and naturally produced aerosols. This is a major step forward in narrowing the uncertainties associated with estimating the total anthropogenic effect on climate. 


\section{The MODIS Aerosol Algorithm, Products and Validation}

L.A. Remer ${ }^{1}$, Y.J. Kaufman ${ }^{1}$, D. Tanré ${ }^{2}$, S. Mattoo ${ }^{1,3}$, D.A. Chu ${ }^{1,3}$, J.V. Martins ${ }^{1,4}$, R-R. Li ${ }^{1,3}$,

C. Ichoku ${ }^{1,3}$, R. C. Levy ${ }^{1,3}$, R.G. Kleidman ${ }^{1,3}$, T.F. Eck ${ }^{7,5}$, E. Vermote ${ }^{7,6}$, B.N. Holben ${ }^{7}$

${ }^{1}$ Laboratory for Atmospheres, NASA/Goddard Space Flight Center, Greenbelt MD

${ }^{2}$ Laboratoire d'Optique Atmospherique, Universite des Sciences et Technologies de Lille,

Villenueve d'Asq, France

${ }^{3}$ Also at Science Systems and Applications Inc., Lanham MD

${ }^{4}$ Also at the Joint Center for Earth Systems Technology, University of Maryland Baltimore County

${ }^{5}$ Also at Goddard Earth Sciences and Technology Center, University of Maryland Baltimore County

${ }^{6}$ Also at Department of Geography, University of Maryland, College Park

${ }^{7}$ Laboratory for Terrestrial Physics, NASA/Goddard Space Flight Center, Greenbelt MD

Corresponding author's address:

Dr. Lorraine Remer

Code 913

NASA/Goddard Space Flight Center

301-614-6194 (voice)

301-614-6307 (fax)

Greenbelt MD 20771

Email: Lorraine.A.Remer@nasa.gov

Submitted for publication, Section "Articles", Journal of the Atmospheric Sciences, Special Issue:

"Chesapeake Lighthouse and Aircraft Measurements for Satellites (CLAMS) Field Experiment" 
Abstract. The MODerate resolution Imaging Spectroradiometer (MODIS) aboard both NASA's Terra and Aqua satellites is making near global daily observations of the earth in a wide spectral range. These measurements are used to derive spectral aerosol optical thickness and aerosol size parameters over both land and ocean. The aerosol products available over land include aerosol optical thickness at three visible wavelengths, a measure of the fraction of aerosol optical thickness attributed to the fine mode and several derived parameters including reflected spectral solar flux at top of atmosphere. Over ocean, the aerosol optical thickness is provided in seven wavelengths from $0.47 \mu \mathrm{m}$ to $2.13 \mu \mathrm{m}$. In addition, quantitative aerosol size information includes effective radius of the aerosol and quantitative fraction of optical thickness attributed to the fine mode. Spectral aerosol flux, mass concentration and number of cloud condensation nuclei round out the list of available aerosol products over the ocean. The spectral optical thickness and effective radius of the aerosol over the ocean are validated by comparison with two years of AERONET data gleaned from 133 AERONET stations. 8000 MODIS aerosol retrievals colocated with AERONET measurements confirm that one-standard deviation of MODIS optical thickness retrievals fall within the predicted uncertainty of $\Delta \tau= \pm 0.03 \pm 0.05 \tau$ over ocean and $\Delta \tau= \pm 0.05 \pm 0.15 \tau$ over land. 271 MODIS aerosol retrievals co-located with AERONET inversions at island and coastal sites suggest that one-standard deviation of MODIS effective radius retrievals falls within $\Delta \mathrm{r}_{-}$eff $= \pm 0.11 \mu \mathrm{m}$. The accuracy of the MODIS retrievals suggests that the product can be used to help narrow the uncertainties associated with aerosol radiative forcing of global climate. 


\section{Introduction}

The Chesapeake Lighthouse and Aircraft Measurements for Satellites (CLAMS) field experiment was designed to aid the development and evaluation of satellite algorithms that retrieve geophysical parameters important to the earth's radiative balance and estimates of global change. Aerosols are one of those important geophysical parameters that are active players in the earth's energy balance and hydrological cycle. These suspended airborne particles scatter solar radiation back to space, absorb solar radiation in the atmosphere and shade the earth's surface. Airborne particles act as cloud condensation nuclei, entering into cloud processes and thereby change cloud reflectivity and the hydrological cycle (Twomey, 1977; Rosenfeld and Lensky, 1998). Aerosols also affect human health and reduce visibility (Samet et al. 2000). Some aerosol types are natural such as wind blown desert dust or sea salt caused by breaking waves. Other aerosol types are created from human activities such as urban/industrial pollution and biomass burning. Unlike $\mathrm{CO}_{2}$, another atmospheric pollutant input into the atmosphere from human activity, aerosols are not well mixed in the atmosphere, and because of their spatial and temporal variability, the uncertainty of estimating human-induced aerosol forcing on climate and the hydrological cycle is huge. Therefore, characterizing global aerosol distribution presents one of our major challenges today (Kaufman, et a1. 2002).

Operational production of aerosol information from long-term satellites provides a means to achieve a global and seasonal characterization of aerosol. Satellites view the entire earth and produce a global image, thus resolving the spatial patterns resulting from the spatial inhomogeneities of aerosol sources. Daily global images from polar orbiting satellites (Husar et al., 1997; Torres et al. 2002) and more frequent imagery from geostationary satellites (Prins et al. 1998) resolve the temporal patterns resulting from the short lifetimes of aerosols, which are on the order of a few days to a week. 
The MODerate resolution Imaging Spectroradiometer (MODIS) is a new sensor with the ability to characterize the spatial and temporal characteristics of the global aerosol field. Launched aboard NASA's Terra and Aqua satellites in December 1999 and May 2002, MODIS has 36 channels spanning the spectral range from 0.44 to $15 \mu \mathrm{m}$. The aerosol retrieval makes use of seven of these channels $(0.47-2.13 \mu \mathrm{m})$ to retrieve aerosol characteristics, and uses additional wavelengths in other parts of the spectrum to identify clouds and river sediments (Ackerman et al., 1998 ; Gao et al., 2002; Li et al. 2003). Cloud identification is also aided by the $500 \mathrm{~m}$ spatial resolution (Martins et al. 2002). Because of the wide spectral range unavailable on previous satellites, MODIS has the unique ability to not only retrieve aerosol optical thickness with greater accuracy, but also to retrieve parameters characterizing aerosol size (Tanré et al. 1996; Tanré et al. 1997). The results section of this paper show that MODIS's ability to separate aerosols by size can be used as a proxy for separating human-generated aerosol from natural sources, which aids substantially in estimating global human-induced aerosol forcing (Kaufman, et al. 2002).

The first MODIS instrument was launched aboard the Terra satellite at the end of 1999 and began transmitting data at the end of February 2000. Algorithms were in place, designed to use the observed radiances to derive many important aerosol products. Early comparisons of the retrieved aerosol parameters with ground-based validation data, showed remarkable agreement between the two types of data (Chu et al. 2002; Remer et al., 2002), but also showed us situations in which the algorithms could be improved. Almost immediately, the algorithms were modified to reflect a better understanding of the instrument's capabilities and the nature of aerosols and clouds. In a companion study in this special issue the MODIS aerosol algorithm over ocean is compared with an independent aerosol retrieval algorithm applied to the same data set of MODIS radiances (Ignatov et al., this issue). In another companion paper in this special issue, the MODIS retrievals over land and ocean are 
evaluated regionally for the specific time and location of the CLAMS field study using the additional resources available during the CLAMS intensive observing period (Levy et al., this issue). However, in the present study we take a global view. We give a comprehensive description of the MODIS aerosol algorithms, highlighting the changes that were implemented post-launch. We describe the wealth of aerosol products derived from MODIS data and available to any user. Lastly, we show some of the global comparisons to ground-based data as validation for the products previously described.

\section{MODIS Aerosol Algorithms}

The MODIS aerosol algorithm is actually two entirely independent algorithms, one for deriving aerosols over land and the second for aerosols over ocean. Both algorithms were conceived and developed before Terra launch and described in depth in Kaufman, et al. (1997b) and Tanré, et al. (1997). In addition, Levy, et al. (2003) provide a more recent description of the over ocean retrieval algorithm. Both the land and ocean aerosol algorithms rely on calibrated, geolocated reflectances provided by the MODIS Characterization Support Team (MCST), identified as products MOD02 and MOD03 for Terra MODIS products and MYD02 and MYD03 for the Aqua MODIS products (MCST 2000; MCST 2002). Ignatov et al. (this issue) provides a good discussion of these reflectances and possible errors associated with them. The Level $1 \mathrm{~b}$ reflectances along with the MODIS cloud mask product identified as MOD/MYD35 (Ackerman et al. 1998), a water vapor product identified as MOD/MYD07 and auxiliary data from NCEP provide the input for the algorithms. The MOD/MYD35 cloud mask product also supplies the earth's surface information that identifies whether a pixel is a "land" pixel or a "water" pixel. Although the algorithm inputs MOD/MYD07 and the NCEP data, it 
can run successfully without these supplements by using climatology for first guess water vapor and ozone profiles.

The theoretical basis of the algorithms has not changed from inception, although some of the mechanics and details of the algorithms have evolved. MODIS data is organized by collections. A collection consists of products that were generated by similar, but not necessarily the same, versions of the algorithm. A complete history of changes to the algorithm over the course of the MODIS mission can be found at http://modis-atmos.gsfc.nasa.gov/MOD04 L2/history.html In this section we will leave the explanation of the theoretical basis of the algorithms to the earlier references, and instead focus on the mechanics of the V4.1.3 algorithm presently in operation, highlighting the changes made since 1997.

\subsection{The Land Algorithm}

Figure 1 illustrates the mechanics of the land algorithm. The MODIS Level lb image, called a granule, consists of a 5-minute swath of MODIS-measured radiances or reflectances. These reflectances are corrected for water vapor, ozone and carbon dioxide before the algorithm proceeds. The first step in deriving aerosol products over land is to organize the measured reflectances of the three MODIS channels used in the procedure: $\rho^{0.47}, \rho^{0.66}$ and $\rho^{2.13}$. All three channels are organized into nominal $10 \mathrm{~km}$ boxes corresponding to 20 by 20 or 400 pixels for each box. This organization requires the $250 \mathrm{~m}$ resolution $0.66 \mu \mathrm{m}$ channel to be degraded to $500 \mathrm{~m}$ in order to match the resolution of the other two channels. The 400 pixels in the box are evaluated

pixel by pixel to determine if the standard MODIS cloud mask (MODIS product MOD35) has identified the pixel as cloudy, as snow/ice or as water. Since launch additional masking has been put 
in place. Because the algorithm is sensitive to small subpixel patches of snow/ice, now all 8 pixels contiguous to a pixel identified as 'snow/ice' by MOD35 will also be labeled as 'snow/ice'. The pixels are further screened for subpixel water by determining the value of the Normalized Difference Vegetation Index (NDVI) for each pixel. Values of NDVI less that 0.10 are identified as containing subpixel water and are excluded along with cloudy and snowy pixels from the remainder of the algorithm.

The second step is to select dark targets and determine their surface reflectance. This process is described in (Kaufman, et al. 1997b), with the following modifications. The algorithm now includes brighter surfaces, which expands the geographical extent of the land retrieval. The reflectance at 3.8 $\mu \mathrm{m}$ is no longer considered, and dark pixels are selected based only on their reflectance at $2.13 \mu \mathrm{m}$. To be selected, a pixel must fall within the range of $0.01 \leq p^{2.13} \leq 0.25$. Experimentation with the operational retrieval showed us that $\rho^{2.13}$ values as bright as 0.25 gave us the same accuracy as the more conservative value of 0.15 initially proposed in (Kaufman, et al. 1997b)). The pixels remaining after masking and dark target selection are then sorted in terms of their visible reflectance, $\rho^{0.66}$. The pixels with the darkest $20 \%$ and brightest $50 \%$ of $\rho^{0.66}$ are discarded. The reason is to eliminate remaining pixels possibly contaminated by cloud shadows or odd surfaces at the dark end or residual cloud contamination and odd surfaces at the bright end. The possibility of residual bright cloud contamination is more common than cloud shadows, thus the filter is skewed towards permitting more dark pixels than bright ones. The remaining $30 \%$ of the pixels will be the ones used in the regular retrieval path, labeled Path $\mathrm{A}$ in Figure 1, but only if there are at least 12 of these pixels remaining from the original 400 in the 20 by 20 box. The mean measured reflectance is calculated from these 12 or more dark target pixels in the three wavelengths $\left(\bar{\rho}^{0.47}, \bar{\rho}^{0.66}\right.$ and $\left.\bar{\rho}^{2.13}\right)$. The surface reflectances at 
$0.47 \mu \mathrm{m}$ and $0.66 \mu \mathrm{m}\left(\rho_{\mathrm{s}}{ }^{0.47}, \rho_{\mathrm{s}}{ }^{0.66}\right)$ are derived from the mean measured $\bar{\rho}^{2.13}$ value using the empirical relationships

$$
\rho_{\mathrm{s}}^{0.47}=0.25 \rho^{2.13} ; \quad \rho_{\mathrm{s}}^{0.66}=0.50 \rho^{2.13}
$$

as described in Kaufman, et al., (1997b) and Kaufman, et al. (1997c). A retrieval following Path A is given a Quality Control value of 3, 'very good'. An alternative path used for brighter surfaces will be described below.

The third step in the standard procedure is to choose an aerosol model and make a retrieval. The estimated surface reflectances $\left(\rho_{s}{ }^{0.47}, \rho^{0.66}\right)$ and the measured mean top-of-atmosphere reflectances $\left(\bar{\rho}^{0.47}, \bar{\rho}^{0.66}\right)$ are used as input into the Continental model Look-Up Table (LUT) to retrieve values for the aerosol optical thickness at 0.47 and $0.66 \mu \mathrm{m}\left(\tau^{0.47}, \tau^{0.66}\right)$. In the land algorithm, the two wavelengths are derived independently. The retrieved optical thicknesses along with the Continental model's single scattering albedoes $\left(\omega_{0}^{0.47}, \omega_{0}^{0.66}\right)$ and phase functions at the appropriate scattering angle $\left(\mathrm{P}^{0.47}, \mathrm{P}^{0.66}\right)$ are used to calculate the path radiance in each wavelength using the following relationship:

$$
\begin{aligned}
& \rho_{o}^{0.47}=\omega_{o}^{0.47} \tau^{0.47} \mathrm{P}^{0.47} ; \\
& \rho_{0}^{0.66}=\omega_{0}^{0.66} \tau^{0.66} \mathrm{P}^{0.66}
\end{aligned}
$$

where $\rho_{0}^{0.47}$ and $\rho_{0}{ }^{0.66}$ are the path radiances at 0.47 and $0.66 \mu \mathrm{m}$, respectively. The spectral dependence of the path radiance distinguishes between dust (dominated by coarse mode) and non-dust (dominated by fine mode). Kaufman, et al. (1997a) describes how the algorithm uses the ratio of path 
radiances, $\rho_{0}^{0.66} / \rho_{0}^{0.47}$ to make a 3-branched decision whether the aerosol is pure dust, non-dust, or mixed. Assuming the continental model does not impact the resulting ratio. It is simply used to remove the molecular and surface contributions and to isolate the aerosol reflectance in both channels. The thresholds for the decision tree are:

$$
\begin{aligned}
& \rho_{\mathrm{o}}^{0.66} / \rho_{\mathrm{o}}^{0.47}<0.72 \text { THEN pure non-dust } \\
& \rho_{0}^{0.66} / \rho_{\mathrm{o}}^{0.47}>0.9-0.01\left(\Theta-150^{\circ}\right) \text { THEN pure dust } \\
& 0.72 \leq \rho_{\mathrm{o}}^{0.66} / \rho_{\mathrm{o}}^{0.47} \leq 0.9-0.01\left(\Theta-150^{\circ}\right) \text { THEN mixed }
\end{aligned}
$$

for scattering angles $\Theta=150^{\circ}$ to $168^{\circ}$. For scattering angles $<150^{\circ}, \Theta$ is simply. set to $150^{\circ}$ for the boundary to collapse to 0.9 in that angle range. If the aerosol is mixed, then the fraction that the fine mode contributes to the total optical thickenss, $\eta=\tau_{f} / \tau_{\text {tot }}$ is given by

$$
\eta=1-\frac{\left[\frac{\underline{\rho}_{o}^{0.66}}{\rho_{o}^{0.47}}-0.72\right]}{0.90-0.01\left(\Theta-150^{\circ}\right)-0.72}
$$

again, where $\Theta$ is set to $150^{\circ}$ when $\Theta<150^{\circ}$. Figure 2 shows four monthly mean values of the fraction of total aerosol optical thickness attributed to the 'non-dust' aerosol model. Red shades indicate that 'non-dust' dominates over the monthly mean. Purple shades indicate that 'pure dust' dominates. Blank areas in black are where no retrievals were made due to too bright a surface, monthly domination by clouds or snow. Note that these plots do not differentiate between high and low aerosol loading. Sensitivity to aerosol size decreases in very clean regions.

Note that 'non-dust' is a misnomer because even though the non-dust aerosol models are dominated by their fine modes, each also contains a coarse mode as well. Three non-dust models are available and are described in Table 1, along with a description of the Continental model and the Dust model. The Urban/industrial model remains unchanged from Kaufman, et al., (1997b) and Remer and Kaufman (1998). The new Developing World - Moderate Absorption model is based on the 
Biomass Burning model of Kaufman, et al. (1997b) and Remer et al. (1998), slightly modified to reflect the more recent study of Dubovik et al. (2002a). The Developing World - Heavy Absorption model uses the same size parameters as the other Developing World Model, but allows for the greater aerosol light absorption noted in Africa (Ichoku et al, 2003; Eck et al. 2003; Dubovik, et al. 2002a). Similar to the original conception of the algorithm, the current version uses season and geography to choose between the three non-dust models (Dubovik et al. 2002a). However, the boundaries have changed. Figure 3 gives the new distribution of the three non-dust models.

If the aerosol is identified as dust by Equation 3, then the dust model of Table 1 is used. However, pure dust poses a problem with the dark target method. The assumption that $\rho^{2.13}$ is transparent to aerosol and provides direct information from the surface does not hold when the aerosol is composed of large particles. Therefore, Equation (1) is not expected to hold in the pure dust case for very dark surfaces. However, over moderately bright surfaces, near the point of critical reflectance ( Kaufman, 1989) the surface contribution is negligible and the procedure can continue with minimal uncertainty introduced from the surface. Therefore, in the pure dust case retrievals are made only when $\rho^{2.13}$ falls between 0.15 and 0.25 .

In both the non-dust and pure dust cases, the estimated surface reflectances $\left(\rho_{s}^{0.47}, \rho_{s}^{0.66}\right)$ and the measured mean top-of-atmosphere reflectances $\left(\bar{\rho}^{0.47}, \bar{\rho}^{0.66}\right)$ are used as input into the chosen model's Look-Up Table (LUT) to retrieve values for the aerosol optical thicknesses, fluxes and other parameters. A full second retrieval is made from the appropriate model's LUT. This second full retrieval differs from Kaufman et al. (1997b) that describes, instead, a correction based on the single scattering approximation to the preliminary Continental model retrieval described above. The final step in the process is to interpolate the values at 0.47 and $0.66 \mu \mathrm{m}$ using an Angstrom law in order to report optical thickness and flux values at $0.55 \mu \mathrm{m}$. 
The standard dark target retrieval path, described above, that uses specific aerosol models requires a minimum of 12 dark pixels in every 20 by 20 pixel nominal $10 \mathrm{~km}$ box. Path B, of Figure 1, represents an alternative if the surface is too bright to support 12 dark pixels in the standard manner. The upper limit of the $\rho^{2.13}$ value is permitted to increase as a function of the slant path. When the sun is at zenith and the satellite-view nadir, Path B collapses back to Path A requirements. However, as the photon path increases, more and more signal originates from the atmosphere, and the contribution from the surface reflectance becomes less and less important. This is especially true at the $0.47 \mu \mathrm{m}$ channel, where atmospheric signal is highest and the surface usually darkest. In Path $\mathrm{B}$, we only retrieve at $0.47 \mu \mathrm{m}$, for this reason. A final upper bound of $\rho^{2.13}=0.40$ is imposed. At least 12 pixels must again meet the Path $\mathrm{B}$ criteria, otherwise the procedure ends with no retrieval made, and fill values are placed in the output fields. Path $\mathrm{B}$ is considered to be less accurate than Path $\mathrm{A}$, and the Quality Control is set to 0 , 'poor quality'. Because of the greater uncertainty over these brighter surfaces and because we retrieve in only one wavelength and cannot use the path radiance ratio to distinguish between dust and non-dust aerosol, only the Continental Model is used in the retrieval. The aerosol optical thickness and flux are derived from the LUT for $0.47 \mu \mathrm{m}$. These parameters are extrapolated to $0.55 \mu \mathrm{m}$ and $0.66 \mu \mathrm{m}$ using the spectral dependence of the Continental Model.

Figure 4 shows a scene from the eastern part of southern Africa, where the surface reflectance is moderately bright. The top panel shows the MODIS retrieval of aerosol optical thickness at $0.55 \mu \mathrm{m}$ following Path A of the algorithm, which insists on 12 dark target pixels. The bottom panel shows the modified version of the algorithm, which allows retrievals over brighter surfaces by following both Path A and Path B. From the image we see how the extension to brighter surfaces fills in holes without introducing suspicious artifacts. In this example, permitting Path B increases the number of retrievals over land from 7060 to 17,849 . As we extend to brighter surfaces, we move away from the biomass 
burning regions into cleaner regions. Thus the mean optical thickness of the granule decreases from 0.20 to 0.15 , but the standard deviation of the optical thickness remains constant at 0.15 . For the 285 granules collected over southern Africa during the SAFARI 2000 campaign, extending to brighter surfaces increases the number of land retrievals by $130 \%$.

\subsection{The Ocean Algorithm}

The mechanics of the ocean algorithm are illustrated in Figure 5. Although the core inversion remains similar to the process described in Tanré, et al. (1997), the masking of clouds and sediments, the special handling of heavy dust including dust retrievals over glint, and revisions of the look-up table are new. As in the land algorithm, after the water vapor, ozone and carbon dioxide corrections are applied, the first step in the ocean algorithm is to organize the reflectance from the six wavelengths used in the procedure $\left(\rho^{0.55}, \rho^{0.66}, \rho^{0.86}, \rho^{1.24}, \rho^{1.6}, \rho^{2.13}\right)$ into nominal $10 \mathrm{~km}$ boxes of 20 by 20 pixels at $500 \mathrm{~m}$ resolution. This requires degrading the resolution of the $250 \mathrm{~m}$ channels $\left(\rho^{0.66}\right.$ and $\left.\rho^{0.86}\right)$. The ocean algorithm requires all 400 pixels in the box to be identified as ocean pixels by the MOD/MYD35 mask. This helps to minimize problems introduced by shallow water near the coasts. If any land is encountered, the entire box is left for the land algorithm.

Cloud and Sediment Masking: If all 400 pixels in the box are identified as water pixels, the algorithm then begins the arduous task of separating 'good' pixels from 'cloudy' pixels. The standard MOD35 cloud mask includes using the brightness in the visible channels to identify clouds. This procedure will mistake heavy aerosol as 'cloudy', and miss retrieving important aerosol events over ocean. On the other hand, relying on IR-tests alone permits low altitude, warm clouds to escape and be misidentified as 'clear', introducing cloud contamination in the aerosol products. Thus, our primary 
cloud mask is based on the difference in spatial variability between aerosols and clouds (Martins, et al. 2002). The algorithm marches through the 10 by 10 box, examining the standard deviation of $\rho^{0.55}$ in every group of 3 by 3 pixels. Any group of 9 pixels with standard deviation greater than 0.0025 is labeled as 'cloudy', and all 9 pixels in the group are discarded (Martins, et al. (2002)). The only exception to this rule is for heavy dust, which may at times be as spatially inhomogeneous as clouds. Heavy dust is identified by its absorption at $0.47 \mu \mathrm{m}$ using the ratio $\left(\rho^{0.47} / \rho^{0.66}\right)$. This quantifies the difference that our eyes witness naturally. Dust absorbs at blue wavelengths and appears brown. Clouds are spectrally neutral and appear white to our eyes. If $\rho^{0.47} / \rho^{0.66}<0.75$, then the central pixel of the group of 9 is identified as 'dust' and will be included in the retrieval even if it is inhomogeneous. This is a conservative threshold that requires very heavy dust in order to avoid clouds. Less restrictive thresholds would permit more dust retrievals, but might accidentally permit cloud contamination.

The spatial variability test separates aerosol from most cloud types, but sometimes fails at the centers of large, thick clouds and also with cirrus, both of which can be spatially smooth. The centers of large, thick clouds are very bright in the visible, and so we identify these clouds when $\rho^{0.47}>0.40$. This is an extremely high threshold that translates into an aerosol optical thickness greater than 5.0, but only for non-absorbing aerosol. Absorbing aerosol never reaches that high value of reflectance and will pass this cloud test unscathed. Some high values of non-absorbing aerosol may be discarded along with bright clouds, but this confusion is rare. Most heavy aerosol loading, with $\tau>5.0$, absorbs somewhat at $0.47 \mu \mathrm{m}$ and fails to reach the 0.40 threshold value, exhibited by very bright white clouds.

Cirrus clouds are identified with a combination of infrared and near-infrared tests. Three infrared tests provided by the standard MODIS cloud mask, MOD35, are examined. These tests are IR cirrus test (byte 2, bit 4 ), $6.7 \mu \mathrm{m}$ test (byte 2, bit 8 ) and Delta IR test (byte 3, bit 3) (Ackerman, et al. 1998). If any one of the 3 indicates cloud, we label the pixel as 'cloudy'. The near-infrared cirrus test 
is based on the reflectance in the $1.38 \mu \mathrm{m}$ channel and the ratio $\rho^{1.38} / \rho^{1.24}$ (Gao, et al. 2002). It is applied in the algorithm as a three step process. If $\rho^{1.38} / \rho^{1.24}>0.3$, then the pixel is 'cloudy'. If 0.10 $\leq \rho^{1.38} / \rho^{1.24} \leq 0.30$ and $\rho^{1.38}>0.03$ and $\rho^{0.66}>1.5 \rho_{\text {Rayleigh, }}^{0.66}$ then the pixels is also 'cloudy'. However, if $0.10 \leq \rho^{1.38} / \rho^{1.24} \leq 0.30$ and $0.01 \leq \rho^{1.38} \leq 0.03$ and $\rho^{0.66}>1.5 \rho_{\text {Rayleigh, then the situation is }}^{0.66}$ ambiguous. The algorithm labels the pixel as 'not cloudy' and will include the pixel in the retrieval process, but the quality of the retrieval (QC) is reduced to 0, 'poor quality'. This permits a retrieval at the orbital level (Level 2), but prohibits the retrieval from contributing to the long-term global aerosol statistics (Level 3). Only retrievals with QC $>0$, contribute to the Level 3 Quality Weighted products. The products and product levels will be explained further in Section 3. Any situation in which the reflectance at $0.66 \mu \mathrm{m} \quad\left(\rho^{0.66}\right)$ does not exceed 1.5 times the Rayleigh reflectance in that channel $\left(\rho_{\text {Rayleigh }}^{0.66}\right)$ or the reflectance at $1.38 \mu \mathrm{m}$ does not exceed 0.01 , then the pixel is assumed to be 'not cloudy' with no ambiguity, unless the ratio $\left(\rho^{1.38} / \rho^{1.24}\right)$ exceeds 0.3 .

The final mask applied to the data is the sediment mask, which identifies which ocean scenes are contaminated by river sediments ( $\mathrm{Li}$ et al, 2002) and discards those pixels. The sediment mask takes advantage of the strong absorption by water at wavelengths longer than $1 \mu \mathrm{m}$. The resulting spectral reflectances over water with suspended sediments thus show elevated values in the visible, but not in the longer wavelengths. This creates an unique spectral signature quite different from clear ocean water and also different from airborne dust.

The algorithm sorts the remaining pixels that have evaded all the cloud masks and the sediment mask according to their $\rho^{0.86}$ value, discards the darkest and brightest $25 \%$, and thereby leaves the middle $50 \%$ of the data. The filter is used to eliminate residual cloud contamination, cloud shadows, or other unusual extreme conditions in the box. Because the ocean cloud mask and the ocean surface 
are expected to be less problematic than their counterparts over land, the filter is less restrictive than the one used in the land retrieval. Of the 400 pixels in the original box, at least 10 must remain from the masking and filtering. Otherwise, no retrieval is attempted and fill values are given for the aerosol products in that $10 \mathrm{~km}$ box. If there are at least 10 good pixels in the $0.86 \mu \mathrm{m}$ channel and at least 30 good pixels in the remaining 5 channels, the mean reflectance and standard deviation are calculated for the remaining 'good' pixels at the six pertinent wavelengths.

Ocean Glint and Internal Consistency: The ocean algorithm was designed to retrieve only over dark ocean, away from glint. There is a special case when we retrieve over glint, and that is described below. The algorithm calculates the glint angle, which denotes the angle of reflection, compared with the specular reflection angle. The glint angle is defined as

$$
\Theta_{\text {glint }}=\cos ^{-1}\left(\left(\cos \theta_{\mathrm{s}} \cos \theta_{\mathrm{v}}\right)+\left(\sin \theta_{\mathrm{s}} \sin \theta_{\mathrm{v}} \cos \phi\right)\right)(6)
$$

where $\theta_{s}, \theta_{v}$, and $\phi$ are the solar zenith, the satellite zenith and the relative azimuth angles (between the sun and satellite), respectively (Levy et al. 2002). Note that Fresnel reflection corresponds to $\Theta_{\text {glint }}=0$. If $\Theta_{\text {glint }}>40^{\circ}$, we can avoid glint contamination and proceed with the retrieval. The algorithm performs several consistency checks of the spectral reflectances. Depending on the outcome of these consistency checks, the algorithm may either declare the reflectances to be beyond the range necessary for a successful inversion and exit the procedure, or continue onto the inversion after assigning quality flags (QC values) to each wavelength.

Inversion Procedure: The inversion procedure is aptly described in Tanré et al. (1997) and Levy et al. (2002). Following Tanré et al. (1996), we know that the 6 reflectances measured from MODIS and used in the ocean retrieval $(0.55-2.13 \mu \mathrm{m})$ contain three pieces of information about the aerosol. From this information we derive three parameters: the optical thickness at one wavelength 
$\left(\tau_{\text {tot }}{ }^{0.55}\right)$, the reflectance weighting parameter at one wavelength $\left(\eta^{0.55}\right)$ and the effective radius, which is the ratio of the $3 \mathrm{rd}$ and 2 nd moments of the aerosol size distribution. The inversion is based on a lookup table (LUT) that now consists of four fine modes and five coarse modes (Table 2, following Levy et al. (2002), which differs from the 11 possible modes listed in Tanre et al. (1997)). The LUT is constructed using the radiative transfer code of Ahmad and Fraser (1982). It consists of the top of atmosphere reflectances in six wavelengths calculated for a variety of geometries, a rough ocean surface with non-zero water-leaving radiance only at $0.55 \mu \mathrm{m}\left(\rho_{\mathrm{s}}^{0.55}=0.005\right)$ and several values of $\tau_{\text {tot }}^{0.55}$ for each single mode aerosol model of Table 2. Note that the LUT is defined in terms of a single wavelength of optical thickness. However, the parameters of each of the single mode models define a unique spectral dependence for that model, which can be applied to the retrieved value of $\tau_{\text {tot }}^{0.55}$ to determine optical thickness at other wavelengths. Table 3 gives the spectral dependence of extinction, asymmetry parameter, and single scattering albedo for each of the modes of Table 2 .

The procedure requires both a fine mode and a coarse mode for each retrieval. The modes from the LUT are combined using $\eta$ as the weighting parameter,

$$
\rho_{\mathrm{LUT}}{ }^{\lambda}\left(\tau_{\text {tot }}^{0.55}\right)=\eta \rho_{\mathrm{f}}^{\lambda}\left(\tau_{\text {tot }}^{0.55}\right)+(1-\eta) \rho_{\mathrm{c}}^{\lambda}\left(\tau_{\text {tot }}^{0.55}\right)
$$

The meaning of Eq. 7 is that the spectral reflectance measured from the satellite that corresponds to the LUT value $\rho_{\mathrm{LUT}}{ }^{\lambda}\left(\tau_{\text {tot }}{ }^{0.55}\right)$ for the determined values of $\eta$ and $\tau_{\text {tot }}^{0.55}$ is a weighted average of the reflectance values for an atmosphere with a pure fine mode ' $f$ ' and optical thickness $\tau_{\text {tot }}^{0.55}$ and the reflectance of an atmosphere with a pure coarse mode ' $c$ ' also with the same $\tau_{\text {tot }}^{0.55}$. The weighting factors are $\eta$ and $1-\eta$. In Appendix $A$, we show that $\eta=\eta^{0.55}$, the fraction of total optical thickness at $0.55 \mu \mathrm{m}$ contributed by the fine mode. 
For each of the twenty combinations of one fine mode and one coarse mode, the inversion finds the pair of $\tau_{\text {tot }}^{0.55}$ and $\eta^{0.55}$ that minimizes the error $(\varepsilon)$ defined as

$$
\varepsilon=\sqrt{\frac{\sum_{\lambda=1}^{6} N^{\lambda}\left(\frac{\rho_{m}^{\lambda}-\rho_{L U T}^{\lambda}}{\rho_{m}^{\lambda}+0.01}\right)^{2}}{\sum_{\lambda=1}^{6} N^{\lambda}}}
$$

where $\mathrm{N}^{\lambda}$ is the sum of good pixels at wavelength $\lambda, \rho_{\mathrm{m}}{ }^{\lambda}$ is the measured MODIS reflectance at wavelength $\lambda$, and $\rho_{\mathrm{LUT}}{ }^{\lambda}$ is calculated from the combination of modes in the look-up table and defined by Equation (7). The 0.01 is to prevent a division by zero for the longer wavelengths under clean conditions (Tanré et al. 1997). The inversion requires $\rho_{\text {LUT }}^{0.87}$ to exactly fit the MODIS observations at that wavelength and then finds the best fits to the other five wavelengths via Equation (8). The $0.87 \mu \mathrm{m}$ channel was chosen to be the primary wavelength because it is expected to be less affected by variability in water leaving radiances than the shorter wavelengths, yet still exhibit a strong aerosol signal, even for aerosols dominated by the fine mode. By emphasizing accuracy in this channel variability in chlorophyll will have negligible effect on the optical thickness retrieval and minimal effect on $\eta^{0.55}$.

The twenty solutions are then sorted according to values of $\varepsilon$. The best solution is the combination of modes with accompanying $\tau_{\text {tot }}^{0.55}$ and $\eta^{0.55}$ that minimizes $\varepsilon$. The solution may not be unique. The average solution is the average of all solutions with $\varepsilon<3 \%$ or if no solution has $\varepsilon<3 \%$, then the average of the 3 best solutions. Once the solutions are found, then the chosen combination of modes is the de facto derived aerosol model and a variety of parameters can be inferred from the chosen size distribution including spectral optical thickness, effective radius, spectral flux, mass concentration, etc. 
Final Checking. Before the final results are output, additional consistency checks are employed. In general, if the retrieved optical thickness at $0.55 \mu \mathrm{m}$ is greater than -0.01 and less than 5 , then the results are output. Negative optical depths are given lower quality flags. There are exceptions and further checking for heavy dust retrievals made over the glint. Quality flags may be adjusted during this final checking phase.

Special case: Heavy dust over glint. If $\Theta_{\text {gint }} \leq 40^{\circ}$ then we check for heavy dust in the glint. We use a similar technique as before during the masking operations when we noted that heavy dust has a distinctive spectral signature because of light absorption at blue wavelengths. In the situation of identifying heavy dust over glint we designate all values of $\rho^{0.47} / \rho^{0.66}<0.95$ to be heavy dust. If heavy dust is identified in the glint, the algorithm continues with the retrieval, although it sets $Q C=0$. This permits the retrieval, but prohibits the values from being included in the Quality Weighted Level 3 statistics. If heavy dust is not identified in the glint, then the algorithm writes fill values to the aerosol product arrays and exits the procedure.

\subsection{The Aerosol Products}

Examples of the three main aerosol products are shown in Figure 6. These three main products are the land and ocean aerosol optical thickness at $0.55 \mu \mathrm{m}\left(\tau^{0.55}\right)$, the fraction of the optical thickness contributed by the fine mode $\left(\eta^{0.55}\right)$ and the reflected flux at the top of the atmosphere at $0.55 \mu \mathrm{m}$. The flux products are hemispherical irradiances at a particular wavelength. Over land, the flux is defined for zero surface reflectance and computed consistently with the same aerosol parameters used in the optical thickness retrieval. Over ocean, the flux is defined for the same rough ocean surface model and the same aerosol parameters derived in the optical thickness retrieval. Errors introduced by inaccurate 
assumptions of the aerosol model during the retrieval when measured radiances at top of atmosphere are converted to optical thickness are subsequently canceled when those same aerosol model assumptions are used with the optical thickness to calculate top of atmosphere fluxes. Errors introduced by assumptions of surface reflectance will remain. Over a monthly average, the consistent calculations produce a highly accurate measure of the flux, more accurate than the optical thickness itself. Figure 6 shows orbital-based Level 2 products, which are cut from 5 minute segments of a satellite orbit, called granules. The Level 2 products, designated as MOD04 files, contain 64 separate products, all connected to the aerosol retrieval. The Level 2 files are produced every day and represent the first level of MODIS aerosol retrieval. In addition, statistics based on the Level 2 aerosol retrievals can also be found in Level 3 files, designated as MOD08 files. These Level 3 files contain parameters produced from the entire MODIS Atmospheres team and include such parameters as water vapor and cloud characteristics along with the aerosol information. The Level 3 data are averaged to a 1-degree latitude/longitude grid and are produced every day (MOD08_D3), averaged every 8 days (MOD08_E3) or averaged on a monthly basis (MOD08_M3). They include both statistics calculated equally from all the data, and also statistics weighted by the quality of each individual retrieval. Quality weights of 0 will prevent poor retrievals from affecting the calculated statistics of the Quality Weighted quantities. Further information about the Level 3 products can be found in (King, et al. 2003)) and at http://atmos-modis.gsfc.nasa.gov.

All together there are 64 aerosol products at Level 2: 9 products describe geometry and location, 3 products are joint land and ocean products, 23 are land-only products and 29 are ocean-only products. Tables 4-7 lists all 64 products. The three joint land and ocean products are simple 2dimensional arrays of one wavelength (Figure 6). The land only and ocean only products contain an additional dimension. In many cases this additional dimension is wavelength. Tables 4-7 list the 
wavelengths for each product, where applicable. The additional dimension in the ocean-only products căn designate either the 'best' solution or the 'average' solution from the ocean retrieval as described above in Section 2.2 (Inversion Procedure). Both solutions are reported for some parameters, although they are often identical.

Tables 4-7 also list whether the product is 'validated', 'not yet validated', 'derived', 'experimental', or 'diagnostic'. A 'validated' product indicates that substantial comparison was made to ground-based data, and that the retrieval is well-characterized so that error bars can be defined and comfortably applied to the retrieval product (Ichoku et al.,2002; Chu et al., 2002; Remer et al. 2002). Examples of validation will be shown in Section 4. 'Not yet validated' indicates that the retrieved parameter has not yet been well-characterized, but that data is being collected and analysis is underway. 'Derived' is a parameter that follows from the retrieval's choice of aerosol model and the magnitude of the retrieved optical thickness. Definitions of some of the derived parameters are given in Appendix B. A 'derived' parameter is not directly retrieved and there are no expectations of ever validating a 'derived' parameter with independent data. 'Experimental' is a scientific product that may have future applications, but as of now is too innovative to be well-characterized. 'Diagnostic' refers to output that is either an auxillary or intermediate parameter. 'Diagnostic' parameters are meant to aid in understanding the final product, but will never themselves become 'validated.'

Recommendations for choosing particular products are given in Appendix C.

\subsection{Validation of Aerosol Products}

Our primary means of validation is comparison with AERONET ground radiometers (Holben, et al. 1998). The AERONET instruments measure spectral aerosol optical thickness, $\tau^{\lambda}$, to within 
$\sim 0.01$ in the MODIS wavelengths (Eck et al., 1999) and can derive ambient, total atmospheric column aerosol effective radius, r_eff, whenever conditions are favorable (Dubovik, et al. 2000). The methodology of comparing temporally varying AERONET data with spatially varying MODIS data is described in (Ichoku et al., 2002). In the following validation, we use AERONET Level 1.5 data, which are cloud screened but not quality assured, primarily because final calibration is not applied (Smirnov, et al. 2000). The procedure that co-locates MODIS and AERONET data is applied during a very short window of opportunity ( $\sim 24$ hours) after the operational MODIS aerosol product has been processed and before that data is transferred to the archive. The data is purged from the operational facility after transfer. It would be a monumental task to retrieve the global data back from the archive to re-link with the AERONET Level 2.0 quality assured data. Figure 7 shows the distribution of the 132 AERONET stations used in the comparisons to be described below. Although North America and Europe provide the most stations in the data base, all continents (except Antarctica), all oceans and all aerosol types are represented.

Validation is an on-going effort. Not only do aerosol conditions vary in location and time, requiring a continued effort to validate the algorithms under various conditions, but the algorithms themselves evolve. The algorithms development and history, starting from the most recent version and going backwards in time can be found at the MODIS atmospheres web site (http://modisatmos.gsfc.nasa.gov/MOD04_L2/history.html). Much of the algorithm modifications concern experimental products, improved cloud/snow/water masking, internal bookkeeping or minor adjustments meant to improve long-term statistics. However, the last adjustment over land to Version 4.1.0 modifies the land look-up tables to increase aerosol absorption as needed in certain regions (Ichoku et al. 2003). This is a significant change, which will not be reflected in the validation plots described below. 
A preliminary validation of the aerosol products was made of the data collected in the first months of operation. The results are reported in Ichoku et al. (2002), Chu et al. (2002) and Remer et al. (2002). The preliminary validation compared 2 to 3 months of MODIS aerosol optical thickness and effective radius retrievals to the same parameters observed (optical thickness) or derived (effective radius) from AERONET radiometers. The preliminary validation from the limited data set showed good agreement between the MODIS-derived parameters and the AERONET parameters.

\subsection{Validation of Aerosol Optical Thickness}

Validation Over Land. Currently there are two years of MODIS aerosol products co-located with AERONET retrievals (August 1, 2000 to August 1, 2002). Figure 8 shows plots of 5906 co-located points over land at wavelengths $0.47 \mu \mathrm{m}, 0.55 \mu \mathrm{m}$ and $0.66 \mu \mathrm{m}$. There are no AERONET measurements at the MODIS wavelengths of $0.47 \mu \mathrm{m}$ and $0.55 \mu \mathrm{m}$; therefore, the AERONET values in the plots of Figure 8 have been interpolated from the values at $0.47 \mu \mathrm{m}$ and $0.87 \mu \mathrm{m}$. The $0.50 \mu \mathrm{m}$ AERONET channel is not used for interpolation because not all AERONET stations have that channel and the procedure that matches MODIS and AERONET data must be uniform and automatic. Although AERONET does make measurements at $0.675 \mu \mathrm{m}$, the values at this wavelength have also been interpolated from $0.44 \mu \mathrm{m}$ and $0.87 \mu \mathrm{m}$, due to occasional calibration drift at this channel in the AERONET instruments. These calibration issues due to gradual filter degradation are identified and corrected in the Quality Assured Level 2 AERONET data, but unfortunately the co-location with MODIS is done in real-processing time and cannot wait for the post-deployment AERONET calibration corrections. Therefore, the $0.675 \mu \mathrm{m}$ is not used and instead the information is transferred from the more reliable $0.44 \mu \mathrm{m}$ and $0.87 \mu \mathrm{m}$ AERONET channels. Also, the MODIS value at 0.55 
$\mu \mathrm{m}$ is not a direct retrieval, but an interpolation from the $0.47 \mu \mathrm{m}$ and $0.66 \mu \mathrm{m}$ retrievals; thus, the plot at $0.55 \mu \mathrm{m}$ in Figure 8 is a comparison of two interpolated values.

Figure 8 represents the scatter plot between MODIS retrievals and AERONET observations, co-located in space and time. The data were sorted according to AERONET aerosol optical thickness. Then an average was calculated for every 300 points and plotted. At higher optical thickness where the data become sparser, fewer points are used in the average, as indicated. The standard deviation in each bin is shown by error bars. The regression equation and correlation given at the top of each plot were calculated from the full scatter plots, before binning. The solid black line is the 1:1 line, and the dashed lines denote the expected uncertainty calculated from pre-launch analysis. These dashed lines should encompass one-standard deviation $(66 \%)$ of the aerosol retrievals. The pre-launch expected uncertainty over land is $\Delta \tau= \pm 0.05 \pm 0.15 \tau$ (Chu et al., 1998; King, et al. 1999). The regression equations in Figure 8 show all wavelengths having an offset greater than the expected offset of 0.05 at low optical thickness, while the plots show a positive bias at low optical thickness suggesting that there is an issue with instrument calibration or more likely, that surface reflectance may be improperly represented in a systematic way at certain locations and seasons. The regression equations also show all wavelengths with slopes less than one. Ichoku et al. 2002 demonstrate that this underprediction of aerosol optical thickness at higher aerosol loadings can be attributed to underpredicting the amount of light absorption by the aerosol in certain regions of the world. This is the reason why the Strong Absorption Model (Table 1) was introduced to the algorithm in the Version 4 delivery. We expect the under prediction of optical thickness at high aerosol loading to be less of an issue after reprocessing with the updated algorithm, but the issue of the offset at low aerosol loading will remain.

Even with the deviations described above, the results of Figure 8 indicate that the algorithm is retrieving aerosol optical thickness over land to roughly within the expected accuracy. On a global 
basis, $61 \%, 68 \%$ and $71 \%$ of the retrievals at the $0.47 \mu \mathrm{m}, 0.55 \mu \mathrm{m}$ and $0.66 \mu \mathrm{m}$, respectively, fall within expected error. From a global perspective, only the blue channel is falling outside of the error bars slightly more often than the pre-launch expectations of $66 \%$. The average $\tau$ at $0.55 \mu \mathrm{m}$ is 0.18 for the land global data base at defined AERONET stations and the percent error between MODIS retrievals and AERONET observations at $0.55 \mu \mathrm{m}$ is $41 \%$, showing a positive bias in which MODIS overestimates $\tau$. The overestimate corroborates the positive offsets seen at low to moderate values of optical thickness in Figure 8. Table 8 shows the percent of retrievals falling within the expected error lines for all the data, and also grouped by specific region. In some regions, the retrievals are more consistently accurate than in other regions. Specifically the North American continent, especially Alaska/Canada is proving to be difficult. This region also exhibits the lowest $\tau$, which contributes to the high relative error. The absolute error in Alaska/Canada is comparable to other regions.

Validation Over Ocean. Similarly to Figure 8 for the land retrievals, Figure 9 represents the scatter plot of 2052 MODIS retrievals over ocean co-located with an AERONET station either on the coast or on an island. Note the dashed lines, denoting expected uncertainty, are narrower than those over land. The MODIS over-ocean algorithm is expected to be more accurate than the over-land algorithm ( $\Delta \tau=$ $\pm 0.03 \pm 0.05 \tau$ ), (Tanré et al., 1999; King et al., 1999). AERONET values at $0.55 \mu \mathrm{m}$ and $0.66 \mu \mathrm{m}$, are interpolated as in Figure 8. No MODIS values are interpolated for these plots, and the $0.87 \mu \mathrm{m}$ plot is the only one showing a directly retrieved MODIS value plotted against a directly measured AERONET value, with no interpolation for either quantity. Unlike the land validation of Figure 8 , the ocean algorithm has virtually no offset and little bias, except for a possible absorbing aerosol bias at high optical thickness suggested in the $0.87 \mu \mathrm{m}$ plot. The linear regression line follows the $1: 1$ line closely through out the optical thickness range where most retrievals occur. 
Table 8 demonstrates the overall higher accuracy of the ocean retrieval when compared to land in that the percent error is consistently smaller over ocean than over land. Globally, $62 \%, 66 \%$ and $70 \%$ of all retrievals over ocean at $0.55 \mu \mathrm{m}, 0.66 \mu \mathrm{m}$ and $0.87 \mu \mathrm{m}$, respectively, are falling within the narrowly defined expected uncertainty. Only the $0.55 \mu \mathrm{m}$ channel is falling outside of the error bars slightly more often than the pre-launch expectations of $66 \%$. The average $\tau$ at $0.55 \mu \mathrm{m}$ is 0.18 for the ocean global data base at defined AERONET stations, the same as for land. Because the land and ocean data bases include many of the same stations, this is not surprising. The percent error between MODIS ocean retrievals and AERONET observations at $0.55 \mu \mathrm{m}$ is only $1 \%$, showing the same absence of bias as exhibited in Figure 9.

Regionally Table 8 shows that the AsianPacific_ocean region and the Saharan_ocean region fall outside the expected uncertainty lines more often than other regions, although for the Sahara it is random scatter with no preference as to over or under prediciting. The aerosols in these regions can have a strong dust component. (Levy et al., 2003) demonstrate that the ocean-algorithm does not perform well in a dust-laden aerosol, attributing the problem to poor assumptions for the dust-aerosol phase functions (ie. Nonsphericity). Empirical non-spherical phase functions have been derived and will be implemented into the next version of the MODIS ocean algorithm. We expect improvements for retrievals in dusty regions to follow from this update.

Discussion of Validation. Comparison of MODIS retrievals with highly accurate ground-based radiometer data validates the basic retrieval, but does not necessarily validate the product for use in long-term climate studies. Figures 8 and 9 cannot validate the MODIS cloud clearing algorithms that play a significant role in the quality of the retrieved aerosol products. Figures 8 and 9 represent the colocated points only for the events in which both the MODIS and the AERONET cloud masking algorithms indicated that no clouds were present. It is possible that MODIS might retrieve, while 
AERONET identified clouds and did not. Those points would not show up on the scatter plots. If those cases were numerous, long-term MODIS aerosol statistics could be cloud-contaminated despite the good agreement in figures 8 and 9.

Figure 10 presents an alternative method of validation that checks the long-term statistics for possible cloud contamination. Here we plot monthly mean values in a 3 degree latitude by 3 degree longitude box centered on the AERONET station. The data is for the year 2001 at eight selected stations, 4 with land components and 4 with only ocean retrievals. Within the 4 land sites, three of them are near enough to the coast to contain sufficient ocean retrievals within the 3 degree by 3 degree box and can be used for testing both land and ocean retrievals. The thick lines, in each plot represent the MODIS aerosol optical thickness at $0.55 \mu \mathrm{m}$ for land (red) and ocean (blue), and the AERONET value (black). The MODIS monthly mean values were calculated from archived MODIS Level 3 data (MOD08) on a 1 degree resolution. Thus, the difficulties with matching MODIS with AERONET in near-real time do not exist, and the monthly AERONET values are calculated from AERONET Level 2.0 data. The data from MODIS and AERONET need not be simultaneous. Despite the nonsimultaneous nature of the measurements, both MODIS and AERONET are expected to represent monthly mean aerosol optical thickness for each region. In this comparison, MODIS does not benefit from AERONET's cloud clearing algorithm. If MODIS retrievals were systematically cloud contaminated, we would expect the MODIS monthly mean values to be systematically higher than AERONET's. This is not the case in any of the 8 regions examined. In most cases, MODIS and AERONET exhibit very similar annual cycles, often with very similar magnitudes of optical thickness. When magnitudes systematically differ, as in Cuiaba-Miranda of Figure 10, it is AERONET that systematically exceeds MODIS. The spatial variability across the 3-degree box can explain some of the differences between instruments. Still, the agreement in optical thickness is striking and suggests 
that MODIS monthly mean optical thickness values are not significantly cloud contaminated and can be used with confidence in developing a global aerosol climatology and estimating aerosol forcing.

\subsection{Validation of Aerosol Size Parameters}

The validation of retrieved size parameters is not as straightforward as validation of optical thickness. Our primary means of validation is to compare with derivations of the same parameter from inversions of AERONET observed sky radiance ((Dubovik et al., 2000)). Sky radiance measurements are taken less often than direct sun measurements in the AERONET protocol. Furthermore, sky radiance data must be sufficiently homogenous and the inversion must make a good fit to the measured radiances in order for the retrieval to be used. As a result there are fewer simultaneous data to be plotted in a scatter plot. Because of this we rely primarily on comparisons of monthly means, which test the applicability of the long-term statistics.

Figure 10 shows comparisons of monthly mean MODIS and AERONET derived $\eta^{0.55}$ (the ratio of fine mode to total optical thickness). These are depicted as the thin lines in the figures, with blue a MODIS ocean derivation, red a MODIS land derivation and black from AERONET. The AERONET values are calculated from standard inversions of AERONET observed sky radiance (Dubovik et al., 2000). The MODIS size parameters over land are not expected to be as accurate as the parameters over ocean, and therefore we focus our discussion on the ocean-derivations shown by the thin blue lines (Tanré et al. 1996). For some sites such as GSFC, Anmyon, and Male, MODIS-ocean and AERONET agree to within $20 \%$ for much of the year. For Bermuda, Midway_Island and Lanai, the agreement is sustained for the first 6 months of the year until MODIS-size parameter jumps to a much lower value. These latter ocean stations exhibit very low optical thickness. The derivation of size parameters at low optical thickness, when aerosol signal is small, will be very sensitive to instrument 
calibration. In June 2001, the MODIS instrument suffered an anomaly and the data processing was switched from the B-side to the A-side electronics. This switch created a small aberration in the calibration that did not affect the more robust optical thickness retrievals, but did affect the size parameter derivations when optical thickness was low.

Comparison of MODIS-derived particle effective radius and AERONET-derived particle effective radius is shown in Figure 11. This plot matches MODIS retrievals to daily averages of Level 2 Quality Assured AERONET sky radiance inversions. The MODIS effective radius parameter is for the total bimodal size distribution in which each of the two modes is weighted by $\eta$ (Appendix B). There were 492 MODIS effective radius retrievals co-located with a daily average AERONET retrieval. However only the 271 match-ups with optical thickness greater than 0.15 are plotted in Figure 12. At low optical thickness there is greater susceptibility to all algorithmic and sensor uncertainties including small calibration errors (discussed above) and retrieval errors for both instruments (Ignatov et al. 1998, Remer et al., 2002). These errors make little difference in optical thickness retrieval but create large errors when size parameters are calculated. Figure 11 shows that $62 \%$ of the points fall within the $\pm 0.10 \mu \mathrm{m}$ errors, which is a smaller percentage than what Remer et al. (2002) reported for a more limited data set. Note that the MODIS and AERONET retrievals both assume spherical particles in deriving size distribution. This assumption causes both MODIS and AERONET to underpredict particle effective radius when non-spherical dust is present (Dubovik et al. 2002b). Thus, the agreement in Figure 11 may be better at some sites if AERONET retrievals had assumed spheroids instead of spheres (Dubovik et al. 2002b). The MODIS algorithm is being modified to include the option of empirical phase functions that do not require any assumption of particle shape. 


\subsection{Results}

Figure 12 illustrates the MODIS aerosol retrievals at the global scale. The images are constructed from the aerosol optical thickness and size parameter products derived from observed MODIS radiances. Red indicates aerosol dominated by small particles (less than $0.5 \mu \mathrm{m}$ ) and greenish tints indicate aerosol with a higher proportion of large particles (greater than $0.5 \mu \mathrm{m}$ ). We can see that aerosol from natural sources, such as sea salt and desert dust, contain larger particles than aerosols emanating from human-produced combustion sources such as agricultural and deforestation burning or urban/industrial pollution. Thus, we see that aerosol size, with the exceptions of lightning-initiated forest fire smoke and ocean DMS production easily separates aerosol into natural and man-made components. Thus we see that MODIS's ability to separate aerosols by size can be used as a proxy for separating anthropogenic aerosol from natural sources, and increases the accuracy of estimating human-induced aerosol forcing (Kaufman, et al. 2002).

\subsection{Conclusions}

Characterizing the global aerosol system is essential to understanding the earth's climate system and estimating potential global climate change. The MODIS instrument flying aboard NASA;s Terra and Aqua satellites provides a look at the aerosol system over both land and ocean on a daily basis. The derivation of aerosol products from the MODIS-measured radiances relies on the broad spectrum MODIS measures, ranging from the visible into the mid-infrared, and the $500 \mathrm{~m}$ spatial resolution, which allows for better cloud identification and clearing than was possible with previous instruments. The mature MODIS algorithm includes aerosol optical thickness at several wavelengths, information 
on particle size, and aerosol reflected flux at the top of the atmosphere, which is expected to be more accurate than the optical thickness retrievals. An extensive validation effort that co-located over 8000 MODIS retrievals with AERONET measurements of optical thickness show that globally, the MODIS products are accurate to within pre-launch expectations. In particular, the retrieval of aerosol over oceans consistently shows remarkably good agreement through the range of optical thickness where most observations occur. Regional analysis shows specific issues for certain locations. Comparison of MODIS and AERONET monthly means at eight specific locations scattered globally demonstrates that the MODIS retrievals are not affected by cloud contamination at those sites, and that MODIS longterm statistics agree well with AERONET and can be used to determine global aerosol climatology. MODIS-derived aerosol size parameters are in general agreement with the same quantities derived by AERONET instruments on the ground. For moderate optical thickness, one-standard deviation of MODIS effective radius retrievals falls within $\pm 0.11 \mu \mathrm{m}$ of AERONET measurements. However, at low aerosol optical thickness $(\tau<0.15)$ the MODIS size retrievals are susceptible to small aberrations in the calibration and other factors which introduce greater uncertainty. In addition, dust, with its nonspherical shapes, introduce uncertainty in both the optical thickness and size parameter retrievals. This latter issue will be addressed with the incorporation of non-spherical phase functions into the next version of the algorithms. In the meantime, the MODIS aerosol products are sufficiently accurate for a variety of applications including improved estimates of observationally based aerosol optical thickness. 


\section{Appendix A: Fraction of fine mode optical thickness.}

One of the most important products produced by the algorithm is the ratio of fine mode optical thickness to the total optical thickness, or simply the fraction of fine mode. Here we show that this fraction at $0.55 \mu \mathrm{m}$ is the same parameter as, $\eta$, the reflectance weighting parameter. We start with equation (7)

$\rho_{\text {LUT }}^{\lambda}\left(\tau_{\text {tot }}^{0.55}\right)=\eta \rho_{\mathrm{f}}^{\lambda}\left(\tau_{\text {tot }}{ }^{0.55}\right)+(1-\eta) \rho_{\mathrm{c}}{ }^{\lambda}\left(\tau_{\text {tot }}^{0.55}\right)$

where $\rho_{\mathrm{f}}^{\lambda}$ and $\rho_{\mathrm{c}}^{\lambda}$ are the fine and coarse mode atmospheric reflectances for the same optical thickness as the total spectral reflectance, $\rho_{\mathrm{Lur}}^{\lambda}$, respectively, and $\eta$ is the reflectance weighting parameter. Note that $\rho_{\mathrm{LUT}}^{\lambda} \neq \rho_{\mathrm{f}}^{\lambda}+\rho_{\mathrm{c}}^{\lambda}$ and that the total and component reflectances all are functions of the total optical thickness $\left(\tau_{\text {tot }}{ }^{0.55}\right)$ not the component optical thicknesses $\left(\tau_{\mathrm{f}}^{0.55}\right.$ and $\left.\tau_{\mathrm{c}}^{0.55}\right)$. All optical thicknesses are defined at $0.55 \mu \mathrm{m}$. This is by definition in constructing the look-up tables.

Define the total optical thickness $\left(\tau_{\text {tot }}^{0.55}\right)$ equal to the sum of the fine $\left(\tau_{\mathrm{f}}^{0.55}\right)$ and coarse $\left(\tau_{\mathrm{c}}^{0.55}\right)$ components. Using the single scattering approximation,

$$
\rho_{\mathrm{f}}^{\lambda}=\mathrm{C} \tau_{\text {tot }}{ }^{0.55} \mathrm{P}_{\mathrm{f}}^{\lambda}, \rho_{\mathrm{c}}{ }^{\lambda}=\mathrm{C} \tau_{\mathrm{tot}}{ }^{0.55} \mathrm{P}_{\mathrm{c}}^{\lambda}
$$

and 


$$
\rho_{\text {LUT }}^{\lambda}=C\left(\tau_{f}^{0.55} P_{f}^{\lambda}+\tau_{c}^{0.55} P_{c}^{\lambda}\right)
$$

where $\mathrm{C}$ is a constant depending on geometry and $\mathrm{P}_{f}^{\lambda}$ and $\mathrm{P}_{c}{ }^{\lambda}$ are the fine mode and coarse mode phase functions calculated for the look-up tables, respectively. There is no $\mathrm{P}_{\text {tot }}{ }^{\lambda}$ because the phase functions in the look-up table are calculated for the collection of individual fine and coarse modes, not for any 'total' aerosol size distribution. Solving for $\eta$ in Equation Al gives,

$$
\eta=\left(\rho_{\text {LUT }}^{\lambda}-\rho_{c}^{\lambda}\right) /\left(\rho_{f}^{\lambda}-\rho_{c}^{\lambda}\right)
$$

Substituting, A2 and A3 into A4 gives

$$
\begin{array}{r}
\eta=\left(C\left(\tau_{f}^{0.55} P_{f}^{\lambda}+\tau_{c}^{0.55} P_{c}^{\lambda}\right)-C \tau_{\text {tot }}{ }^{0.55} P_{c}^{\lambda}\right) / \\
\left(C \tau_{\text {tot }}{ }^{0.55} P_{f}^{\lambda}-C \tau_{\text {tot }}{ }^{0.55} P_{c}{ }^{\lambda}\right)
\end{array}
$$

Dropping the constant ' $\mathrm{C}$ ' and using the definition of $\tau_{\text {tot }}{ }^{0.55}=\tau_{\mathrm{f}}^{0.55}+\tau_{\mathrm{c}}^{0.55}$ gives

$$
\begin{gathered}
\left.\eta=\left(\tau_{\mathrm{f}}^{0.55} \mathrm{P}_{\mathrm{f}}^{\lambda}+\tau_{\mathrm{c}}^{0.55} \mathrm{P}_{\mathrm{c}}^{\lambda}\right)-\tau_{\mathrm{f}}^{0.55} \mathrm{P}_{\mathrm{c}}^{\lambda}-\tau_{\mathrm{c}}^{0.55} \mathrm{P}_{\mathrm{c}}{ }^{\lambda}\right) / \\
{\left[\tau_{\mathrm{tot}}^{0.55}\left(\mathrm{P}_{\mathrm{f}}^{\lambda}-\mathrm{P}_{\mathrm{c}}^{\lambda}\right)\right]}
\end{gathered}
$$

$$
\eta=\tau_{f}^{0.55}\left(\mathrm{P}_{f}^{\lambda}-\mathrm{P}_{\mathrm{c}}^{\lambda}\right) /\left[\tau_{\text {tot }}^{0.55}\left(\mathrm{P}_{f}^{\lambda}-\mathrm{P}_{c}^{\lambda}\right)\right]
$$

$$
\eta=\tau_{\mathrm{f}}^{0.55} / \tau_{\text {tot }}{ }^{0.55}
$$


Thus the reflectance weighting factor, $\eta$, is also the ratio between fine mode and total optical thickness at $0.55 \mu \mathrm{m}$, as defined within the parameters of the inversion. 


\section{Appendix B: Definitions of Derived Parameters}

The following give the formulas for derivation of the derived parameters. In these formulas $n(r)$ is the size distribution with $r$ denoting radius. $r_{\mathfrak{g}}$ is the geometric mean radius. $N_{o}$ is number of particles per cross section of the atmospheric column (the amplitude of the number size distribution of a lognormal) that can be converted from $V_{0}$ of the volume size distributions for each lognormal mode using $\mathrm{N}_{\mathrm{O}}=\frac{3 \sigma \mathrm{V}_{\mathrm{O}} \sqrt{2 \pi}}{4 \pi} \mathrm{r}_{\mathrm{g}}^{-3} \exp \left(-\frac{9}{2} \sigma^{2}\right)$

$\beta s$ is the scattering coefficient, specific to each model mode. $\rho$ is the density of the particle assumed to be $1 \mathrm{~g} / \mathrm{cm}^{3}$. erf() is the error function. $\sigma$ is $\ln \sigma_{\mathrm{g}}$ where $\sigma_{\mathrm{g}}$ is the geometric mean standard deviation of the lognormal distribution. $\mu$ is $\cos \theta$, and $\theta$ is the scattering angle. $\mathrm{P}()$ is the phase function.

$\tau$ is the optical thickness and unless designated specifically for wavelength or large or small mode, represents the total optical thickness at $0.55 \mu \mathrm{m}$. Extcoeff is the extinction coefficient and unless designated specifically for wavelength is understood to be $0.55 \mu \mathrm{m}$.

Cloud condensation nuclei in units of $\mathrm{cm}^{-2}$,

$\mathrm{CCN}=\int_{\mathrm{T}_{0}}^{\infty}=0.03 \mu \mathrm{m} n(\mathrm{r}) \mathrm{dr}=0.5 \times 10^{-10}\left(1-\operatorname{erf}\left\{\frac{\ln \left(\mathrm{r}_{0} / \mathrm{r}_{\mathrm{g}}\right)}{\sqrt{2} \sigma}\right\}\right)$

Assymetry factor,

$g_{\lambda}=0.5 \int_{-1}^{1} \mu P_{\lambda}(\mu) d \mu=0.5 \int_{0}^{\pi} \cos (\theta) P_{\lambda}(\theta) \sin \theta d \theta$

Backscattering ratio, 
$\beta_{\lambda}=\frac{1}{2 \pi} \int_{-1}^{1} \frac{1}{\mu} \mathrm{P}(\mu) \mathrm{d} \mu=\frac{1}{2 \pi} \int_{0}^{\pi} \theta \mathrm{P}(\theta) \sin \theta \mathrm{d} \theta$

Number of particles in each mode $\left(1\right.$ particle $\left./ \mathrm{cm}^{3}\right) . \tau$ and extcoeff defined at $0.55 \mu \mathrm{m}$,

$$
N_{\text {small }}=\frac{\tau_{\text {small }}}{\text { extcoeff } f_{\text {small }}} \quad N_{\text {large }}=\frac{\tau_{\text {large }}}{\text { extcoefflarge }}
$$

Moments of $\mathrm{M}^{\mathrm{k}}$ of order $\mathrm{k}$,

$M^{k}=\int_{0}^{\infty} r^{k} n(r) d r=\left(r_{g}\right)^{k} \exp \left(0.5 k^{2} \sigma^{2}\right)$

Effective radius $(\mu \mathrm{m})$,

$r_{\text {eff }}=\left(N_{\text {small }} M_{\text {small }}^{3}+N_{\text {large }} M_{\text {large }}^{3}\right) /\left(N_{\text {small }} M_{\text {small }}^{2}+N_{\text {large }} M_{\text {large }}^{2}\right)$

Mass concentration $\left(\mu \mathrm{g} / \mathrm{cm}^{2}\right)$,

Mass_conc $=\left(N_{\text {small }} M_{\text {small }}^{3}+N_{\text {large }} M_{\text {large }}^{3}\right) /\left(N_{\text {small }}+N_{\text {large }}\right) \quad$ Over ocean

Mass_conc $=\frac{N_{\mathrm{o}}}{\beta_{\mathrm{s}}} \rho\left(\frac{4}{3} \pi \mathrm{r}_{\mathrm{g}}^{3}\right) \tau \quad$ Over land

Angstrom exponent $1(0.55 / 0.87)$ and Angstrom exponent $2(0.87 / 2.13)$,

$$
\begin{aligned}
& \text { AngExp_1 } 1=\frac{\ln \left(\frac{\tau_{0.55}}{\tau_{0.87}}\right)}{\ln \left(\frac{0.55}{0.87}\right)} \\
& \text { AngExp_2 } 2=\frac{\ln \left(\frac{\tau_{0.87}}{\tau_{2.13}}\right)}{\ln \left(\frac{0.87}{2.13}\right)}
\end{aligned}
$$




\section{Appendix C: Recommendations For Using Products:}

There are many choices for aerosol optical thickness. The products In Tables $4-7$ labeled as 'validated', 'not yet validated', or 'derived' are recommended. 'Corrected_Optical_Depth_Land' is the recommended spectral product over land, and 'Effective_Optical_Depth_Average_Ocean' is the recommended spectral product over ocean. Products such as 'Continental_Optical_Depth_Land' are intermediate parameters and should be used only as a diagnostic.

The word 'small' in the product name indicates fine mode so that 'Optical_Depth_Small' is the fine mode optical thickness, $\tau^{\mathrm{f}}$, from Appendix A, 'Optical_Depth_Ratio_Small' is the fine mode ratio, $\eta^{\lambda}$. Likewise, the word 'large' indicates coarse mode. The word 'Average' indicates the solution averaged from all retrieval solutions with fitting error less than $3 \%$ or the average of the 3 best solutions if all $\varepsilon$ $>3 \%$. The word 'best' indicates the single solution with the least error, $\varepsilon$, no matter how large. See equation 7. The recommendation is to use those products labeled as 'average'.

The Angstrom Exponent over land is defined for wavelengths 0.47 and $0.66 \mu \mathrm{m}$. There are two Angstrom Exponents for the ocean parameters, one defined using wavelengths 0.55 and $0.87 \mu \mathrm{m}$ and the other using $0.87 \mu \mathrm{m}$ and $2.13 \mu \mathrm{m}$.

'Aerosol_Type' under the land products is a function mostly of geography and season and should not be considered a retrieved quantity. The 'Cloud_Fraction' listed in the tables is not a true cloud fraction, but instead an indication of the fraction of pixels not used in the retrieval due to a combination of clouds, surface issues or internal inconsistencies. Likewise, 'Mean_Reflectance' is the mean reflectance only of those pixels that survive the masking and elimination procedures and are actually used in the retrievals. Solution_Index tells which fine and coarse aerosol models were chosen in the retrieval. Least_Squares_Error reports the fitting error of the inversion, $\varepsilon$, from Equation 7. 
The 'Quality_Assurance' parameters are 5-byte codes that hold information concerning the retrievals and the overall quality. Details of the 'Quality_Assurance' code are given by the MODIS Atmosphere's Quality Assurance Plan that can be found at http://modis-atmos.gsfc.nasa.gov. The top bit of the Quality Assurance code is the most important. If this top bit equals 0 , then the retrieval at that location is experimental. It may be set to 0 because the surface was bright and Path B of Figure 2 was followed, or it may be a special heavy dust retrieval over ocean. Mostly these experimental retrievals provide excellent results, but sometimes they do not, and the user should be cautious when using data with Quality of 0 . 


\section{References:}

Ackerman, S.A., K.I. Strabala, W.P. Menzel, R.A. Frey, C.C. Moeller and L.E. Gumley, 1998: Discriminating clear sky from clouds with MODIS. J. Geophys. Res., 103, 32139-32140.

Chu, D.A., Y.J. Kaufman, L.A. Remer and B.N. Holben, 1998: Remote sensing of smoke from MODIS airborne simulator during the SCAR-B experiment. J. Geophys. Res., 103, 31,97931,988 .

Chu, D.A., Y.J. Kaufman, C. Ichoku, L.A. Remer, D. Tanre and B.N. Holben, 2002: Validation of MODIS aerosol optical depth retrieval over land. Geophys. Res. Lett., 29 , 10.1029/2001GL013205.

Dubovik, O., A. Smirnov, B.N. Holben, M.D. King, Y.J. Kaufman, T.F. Eck and I. Slutsker, 2000a: Accuracy assesments of aerosol optical properties retrieved from AERONET Sun and skyradiance measurements. J. Geophys. Res., 105, 9791-9806.

Dubovik, O., B.N. Holben, T.F. Eck, A. Smirnov, Y.J. Kaufman, M.D. King, D. Tanré and I. Slutsker, 2002b: Variability of absorption and optical properties of key aerosol types observed in worldwide locations. J. Atmos. Sci., 59, 590-608.

Dubovik, O., B.N. Holben, T. Lapyonok, A. Sinyk, M.I. Mishchenko, P. Yang and I. Slutsker, 2002: Non-spherical aerosol retrieval metod employing light scattering by spheroids. Geophys. Res. Lett., 29, 10.1029/2001GL014506.

Eck, T.F., B.N. Holben, J.S. Reid, O. Dubovik, A. Smirnov, N.T. O'Neill, I. Slutsker and S. Kinne, 1999: Wavelength dependence of the optical depth of biomass burning, urban and desert dust aerosols. J. Geophys. Res., 104, 31,333-31,349. 
Eck, T.F., B.N. Holben, D.E. Ward, M.M. Mukelabai, O. Dubovik, A. Smirnov, J.S. Schafer, N.C. Hsu, S.J. Piketh, A. Qeface, J.L. Roux, R.J. Swap and I. Slutsker, 2003: Variability of biomass burning aerosol optical characteristics in southern Africa during the SAFARI 2000 dry season campaign and a comparison of single scattering albedo estimates from radiometric measurements. J. Geophys. Res., 108, 10.1029/2002JD002321.

Gao, B.-C., Y.J. Kaufman, D. Tanré and R.-R. Li, 2002: Distinguishing tropospheric aerosols from thin cirrus clouds for improved aerosol retrievals using the ratio of $1.38-\mu \mathrm{m}$ and $1.24-\mu \mathrm{m}$ channels. Geophys. Res. Lett., 29, 1890, doi:10.1029/2002GL015475.

Herman, J.R., P.K. Bhartia, O. Torres, C. Hsu, C. Seftor and E. Celarier, 1997: Global distribution of UV-absorbing aerosols from Nimbus 7/TOMS data. J. Geophys. Res., 102, 16911-16922.

Holben, B.N., T.F. Eck, I. Slutsker, D. Tanré, J.P. Buis, A. Setzer, E. Vermote, J.A. Reagan, Y.J. Kaufman, T. Nakajima, F. Lavenu, I. Jankowiak and A. Smirnov, 1998: AERONET--A federated instrument network and data archive for aerosol characterization. Rem. Sens. Environ., 66, 1-16.

Husar, R.B., L.L. Stowe and J.M. Prospero, 1997: Characterization of tropospheric aerosols over the oceans with the NOAA advanced very high resolution radiometer optical thickness operational product. J. Geophys. Res., 102, 16889-16910.

Ichoku, C., D.A. Chu, S. Mattoo, Y.J. Kaufman, L.A. Remer, D. Tanré, I. Slutsker and B.N. Holben, 2002: A spatio-temporal approach for global validation and analysis of MODIS aerosol products. Geophys. Res. Lett., 29, 10.1029/2001GL013206.

Ichoku, C., L.A. Remer, Y.J. Kaufman, R. Levy, D.A. Chu, D. Tanré and B.N. Holben, 2003: MODIS observation of aerosols and estimation of aerosol radiative forcing over southern Africa during SAFARI 2000. J. Geophys. Res., 108, 10.1029/2002JD002366. 
Ignatov, A., P. Minnis, N. Loeb, B. Wielicki, W. Miller, S. Sun-Mack, D. Tanré, L. Remer, I. Laszlo and E. Geier, 2004: Two MODIS aerosol productsover ocean on the Terra and Aqua CERES SSF data sets. J. Atmos. Sci., submitted to CLAMS special issue,

Kaufman, Y.J., 1989: The atmospheric effect on remote sensing and its correction. In Theory and Applications of Optical Remote Sensing, John Wiley \& Sons, New York, G. Asrar, editor, 336428.

Kaufman, Y.J., D. Tanré, H.R. Gordon, T. Nakajima, J. Lenoble, R. Frouin, H. Grassl, B.M. Herman, M.D. King and P.M. Teillet, 1997a: Passive remote sensing of tropospheric aerosol and atmospheric correction for the aerosol effect. J. Geophys. Res., 102, 16815-16830.

Kaufman, Y.J., D. Tanré, L.A. Remer, E. Vermote, A. Chu and B.N. Holben, 1997b: Operational remote sensing of tropospheric aerosol over land from EOS moderate resolution imaging spectroradiometer. J. Geophys. Res., 102, 17051-17067.

Kaufman, Y.J., A.E. Wald, L.A. Remer, B.-C. Gao, R.-R. Li and L. Flynn, 1997c: The MODIS $2.1 \mu \mathrm{m}$ Channel - Correlation with visible reflectance for use in remote sensing of aerosol. IEEE Trans. Geo, 35, 1286-1298.

Kaufman, Y.J., D. Tanré and O. Boucher, 2002: A satellite view of aerosols in the climate system. Nature, 419, 215-223.

King, M.D., Y.J. Kaufman, D. Tanré and T. Nakajima, 1999: Remote sensing of tropospheric aerosols from space: Past, present, and future. B. Am. Meteor. Soc., 80, 2229-2259.

King, M.D., W.P. Menzel, Y.J. Kaufman, D. Tanré, B.-C. Gao, S. Platnick, S.A. Ackerman, L.A. Remer, R. Pincus and P.A. Hubanks, 2003: Cloud and aerosol properties, precipitable water, and profiles of temperature and humidity from MODIS. IEEE Trans. Geosci. Remote Sens., 41, $442-458$. 
Levy, R.C., L.A. Remer, D. Tanré, Y.J. Kaufman, C. Ichoku, B.N. Holben, J.M. Livingston, P.B. Russell and H. Maring, 2003: Evaluation of the MODIS retrievals of dust aerosol over the ocean during PRIDE. J. Geophys. Res., 108 (D14), 10.1029/2002JD002460

Levy, R.C., L.A. Remer, J.V. Martins, Y.J. Kaufman, A. Plana-Fattori, J. Redemann, P.B. Russell and B. Wenny, 2004: Evaluation of the MODIS aerosol retrievals over ocean and land during CLAMS. J. Atmos. Sci., CLAMS special issue,

Li, R.-R., Y.J. Kaufman, B.-C. Gao and C.O. Davis, 2003: Remote sensing of suspended sediments and shallow coastal waters. IEEE TGARS, 41, 559-566.

Martins, J.V., D. Tanré, L.A. Remer, Y.J. Kaufman, S. Mattoo and R. Levy, 2002: MODIS Cloud screening for remote sensing of aerosol over oceans using spatial variability. Geophys. Res. Lett., 29, 10.1029/2001GL013252.

MCST (MODIS Characterization Support Team), 2000: MODIS Level 1B Product User's Guide, for Level 1B Version 2.3.x, Release 2. MCST Document \#PUB-01-U-DNCN., Available on line at http://www.mcst.ssai.biz/mcstweb/L1B/product.html.

MCST (MODIS Characterization Support Team), 2002: MODIS Level 1B Product User's Guide, for Level 1B Version 4.0.9 (Terra) and Version 4.1.1 (Aqua). MCST Document \#PUB-01-U-0202REV B (MCST Internal Memorandum \#M1039., Available on line at http://www.mcst.ssai.biz/mcstweb/L1B/product.html.

Prins, E.M., J.M. Feltz, W.P. Menzel and D.E. Ward, 1998: An overview of GOES-8 diurnal fire and smoke results for SCAR-B and 1995 fire season in South America. J. Geophys. Res., 103, $31,821-31,836$.

Remer, L.A. and Y.J. Kaufman, 1998: Dynamical aerosol model: Urban/industrial aerosol. J. Geophys. Res., 103, 13,859-13,871. 
Remer, L.A., Y.J. Kaufman, B.N. Holben, A.M. Thompson and D. McNamara, 1998: A model of tropical biomass burning smoke aerosol size distribution. J. Geophys. Res., 103, 31,879-31,892.

Remer, L.A., D. Tanré, Y.J. Kaufman, C. Ichoku, S. Mattoo, R. Levy, D.A. Chu, B.N. Holben, O. Dubovik, A. Smirnov, J.V. Martins, R.-R. Li and Z. Ahmad, 2002: Validation of MODIS aerosol retrieval over ocean. Geophys. Res. Lett., 29, 10.1029/2001GL013204.

Rosenfeld, D. and I.M. Lensky, 1998: Satellite-based insights into precipitation formation processes in continental and maritime convective clouds. Bull. Am. Meteor. Soc., 79, 2457-2476.

Samet, J.M., S.L. Zeger, F. Dominici, F. Curriero, I. Coursac, D.W. Dockery, J. Schwartz and A. Zanobetti, 2000: The national morbidity, mortality, and air pollution study, Part II: Morbidity, Mortality and Air Pollution in the United States. Health Effects Institute Research Report, Cambridge MA, Number 94, Part II, 87 pp.

Smirnov, A., B.N. Holben; T.F. Eck, O. Dubovik and I. Slutsker, 2000: Cloud-screening and qualtity control algorithms for the AERONET database. Rem.Sens. Environ., 73, 337-349.

Tanré, D., M. Herman and Y.J. Kaufman, 1996: Information on aerosol size distribution contained in solar reflected spectral radiances. J. Geophys. Res., 101, 19043-19060.

Tanré, D., Y.J. Kaufman, M. Herman and S. Mattoo, 1997: Remote sensing of aerosol properties over oceans using the MODIS/EOS spectral radiances. J. Geophys. Res., 102, 16971-16988.

Tanré, D., L.A. Remer, Y.J. Kaufman, S. Mattoo, P.V. Hobbs, J.M. Livingston, P.B. Russell and A. Smirnov, 1999: Retrieval of aerosol optical thickness and size distribution over ocean from the MODIS Airbome Simulator during TARFOX. J. Geophys. Res., 104, 2261-2278.

Torres, O., P.K. Bhartia, J.R. Herman, A. Sinyuk, P. Ginoux and B. Holben, 2002: A long-term record of aerosol optical depth from TOMS observations and comparison to AERONET measurements. J. Atmos. Sci., 59, 398-413. 
Twomey, S.A., 1977: The influence of pollution on the shortwave albedo of clouds. J. Atmos. Sci., 34, 1149-1152. 


\section{Table Captions}

Table 1. Size Distribution Parameters, and Single Scattering Albedo Used in the MODIS Look Up Table for the Land Algorithm.

Table 2. Refractive Indices, Median, Standard Deviation and Effective Radius for the aerosol models used in the MODIS Lookup Table for the ocean algorithm. Models 1-4 are fine modes and Models 5-9 are coarse modes.

Table 3. Values of Assymetry parameter and Single Scattering Albedo for the 9 ocean models of Table 2.

Table 4. Contents of MODIS Aerosol Level 2 hdf file (MOD04): Time and geometric information

Table 5. Contents of MODIS Aerosol Level 2 hdf file (MOD04): Global land and ocean products, at $0.55 \mu \mathrm{m}$

Table 6. Contents of MODIS Aerosol Level 2 hdf file (MOD04): Land products

Table 7. Contents of MODIS Aerosol Level 2 hdf file (MOD04): Ocean products

Table 8. Number of retrievals $(N)$, percentage of retrievals (\%) falling within expected uncertainty for each ( wavelength, average optical thickness from AERONET $\left(\tau^{550}\right)$ and percent difference between MODIS and AERONET at $0.55 \mu \mathrm{m}$ (Diff) for the global data set and for each region, land and ocean separately. 


\section{Figure Captions}

Figure 1. Flowchart illustrating the derivation of aerosol over land.

Figure 2. Monthly mean plots of fraction of total aerosol optical thickness attributed to 'non-dust' or fine mode aerosol over land. Fraction 1.0 indicates all fine mode. Fraction of 0.0 indicates all coarse mode.

Figure 3. Distribution of the non-dust models used in the derivation of aerosol over land. Single scattering albedo values given in parentheses. Uncolored regions use the urban/industrial aerosol model. Solid black regions use the moderate absorption aerosol model all year. Large checkerboard pattern in east Asia denotes a region of strong absorption aerosol model all year. Africa is divided by region and season. North of the equator, during the burning season (November-May) the strong absorption aerosol model is used, while the moderate absorption model is used the remainder of the year. South of the equator, the burning season shifts to June-October when the strong absorption model is used, while in the remainder of the year the algorithm uses the urban/industrial model.

Figure 4. MODIS-derived aerosol optical thickness at $0.55 \mu \mathrm{m}$ for an image of the east coast of southern Africa. Top panel uses the traditional dark target method described by Path A in Figure 2. The bottom panel shows the results after extending the retrieval to brighter surfaces as described by Path B of Figure 2. By extending to brighter surfaces the number of retrievals over land in this image increases from 7060 to 17,849 .

Figure 5. Flowchart illustrating the derivation of aerosol over ocean. 
Figure 6. Examples of MODIS aerosol products at the Level 2 stage (MOD04). The data represent a 5 minute granule collected on July 7, 2002 from 1835-1840 UTC. The upper left panel is a true color image created from Level $1 \mathrm{~b}$ reflectances. The upper right panel is aerosol optical thickness at $550 \mathrm{~nm}$, The lower left panel is reflected flux at $550 \mathrm{~nm}$. The lower right panel is fraction of fine mode.

Figure 7. The distribution of the 132 AERONET stations used to validate MODIS land and ocean aerosol retrieval algorithms.

Figure 8. MODIS aerosol optical thickness retrievals over land at $470 \mathrm{~nm}$ (blue), $550 \mathrm{~nm}$ (green ) and 660 $\mathrm{nm}$ (red) as a function of AERONET observations co-located in space and time. The data were sorted according to AERONET aerosol optical thickness and averaged for every 300 points. At higher optical thickness where the data become sparser, fewer points are used in the average, as indicated. The standard deviation in each bin is shown by error bars. The regression equations given at the top of each plot were calculated from the full scatter plots before binning. The solid black line is the $1: 1$ line and the dashed lines denote the expected uncertainty calculated from pre-launch analysis.

Figure 9. MODIS aerosol optical thickness retrievals over ocean at $550 \mathrm{~nm}$ (green ) and $660 \mathrm{~nm}$ (red) and $870 \mathrm{~nm}$ (black) as a function of AERONET observations co-located in space and time. The data were sorted according to AERONET aerosol optical thickness and averaged for every 100 points. At higher optical thickness where the data become sparser, fewer points are used in the average, as indicated. The standard deviation in each bin is shown by error bars. The regression equations given at the top of each 
plot were calculated from the full scatter plots before binning. The solid black line is the 1:1 line and the dashed lines denote the expected uncertainty calculated from pre-launch analysis.

Figure 10. Monthly mean aerosol optical thickness at $0.55 \mu \mathrm{m}$ (heavy lines and left hand axes) and fraction of optical thickness contributed by fine mode at $0.55 \mu \mathrm{m}$ (thin lines and right hand axes) for the year 2001. Blue denotes MODIS ocean retrievals. Red denotes MODIS land retrievals, and black denotes AERONET. Four land stations are shown in (a) and four ocean stations are shown in (b). The MODIS values are calculated from Level 3 daily statistics and represent a 3 degree latitude by 3 degree longitude box centered on the AERONET station.

Figure 11. MODIS retrieved aerosol particle effective radius over ocean plotted against AERONET retrievals of the same parameter. Only points with AERONET $\tau^{0.44}>0.15$ are plotted. AERONET values are daily averages for the date of the MODIS overpass. The blue line represents the linear regression through the points. The solid black line is the $1: 1$ line and the dashed lines represent $\pm 0.10 \mu \mathrm{m} .271 \mathrm{co}-$ located points are shown. $62 \%$ of these points fall within the dashed lines.

Figure 12. MODIS aerosol optical thickness at $0.55 \mu \mathrm{m}$, representing global aerosol distribution on August 12, 2001. The two dimensional color bar describes both magnitude of optical thickness (along bottom axis) and fraction of optical thickness contributed by smaller fine mode particles (along vertical axis). Blue indicates low aerosol loading. Red indicates heavy loading of small particles such as pollution and smoke. The greener tones indicate a greater percentage of large particles such as desert dust and sea salt. The image was created from the MODIS daily $10-\mathrm{km}$ resolution data after smoothing the raw data with Gaussian filters applied both in the temporal and spatial domains. 
Table 1. Size Distribution Parameters, and Single Scattering Albedo Used in the MODIS Look Up Table for the Land Algorithm.

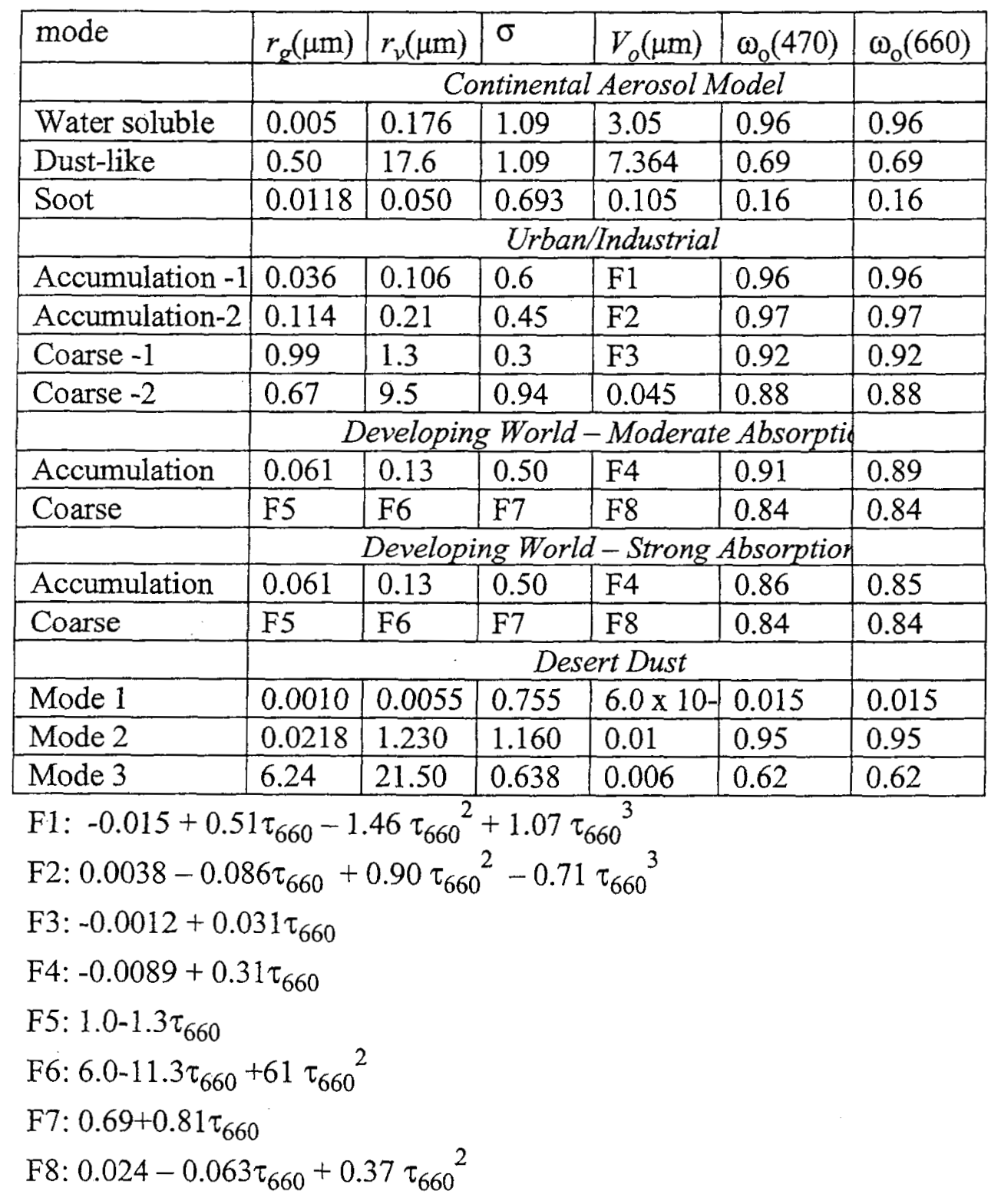


Table 2: Refractive Indices, Median, Standard Deviation and Effective Radius for the aerosol models used in the MODIS Lookup Table for the ocean algorithm.

Models 1-4 are fine modes and Models 5-9 are coarse modes.

\begin{tabular}{|c|c|c|c|c|c|c|c|c|}
\hline & $\lambda=0.47->0.86 \mu \mathrm{m}$ & $\lambda=1.24 \mu \mathrm{m}$ & $\lambda=1.64 \mu \mathrm{m}$ & $\lambda=2.13 \mu \mathrm{m}$ & $\mathrm{r}_{\mathrm{g}}$ & $\sigma$ & $\mathrm{r}_{\text {eff }}$ & Comments \\
\hline \hline 1 & $1.45-0.0035 \mathrm{i}$ & $1.45-0.0035 \mathrm{i}$ & $1.43-0.01 \mathrm{i}$ & $1.40-0.005 \mathrm{i}$ & 0.07 & 0.40 & 0.10 & $\begin{array}{c}\text { Wet Water } \\
\text { Soluble type }\end{array}$ \\
\hline 2 & $1.45-0.0035 \mathrm{i}$ & $1.45-0.0035 \mathrm{i}$ & $1.43-0.01 \mathrm{i}$ & $1.40-0.005 \mathrm{i}$ & 0.06 & 0.60 & 0.15 & $\begin{array}{c}\text { Wet Water } \\
\text { Soluble type }\end{array}$ \\
\hline 3 & $1.40-0.0020 \mathrm{i}$ & $1.40-0.0020 \mathrm{i}$ & $1.39-0.005 \mathrm{i}$ & $1.36-0.003 \mathrm{i}$ & 0.08 & 0.60 & 0.20 & $\begin{array}{c}\text { Water Soluble } \\
\text { with humidity }\end{array}$ \\
\hline 4 & $1.40-0.0020 \mathrm{i}$ & $1.40-0.0020 \mathrm{i}$ & $1.39-0.005 \mathrm{i}$ & $1.36-0.003 \mathrm{i}$ & 0.10 & 0.60 & 0.25 & $\begin{array}{c}\text { Water Soluble } \\
\text { with humidity }\end{array}$ \\
\hline
\end{tabular}

\begin{tabular}{|c|c|c|c|c|c|c|c|c|}
\hline & $\lambda=0.47->0.86 \mu \mathrm{m}$ & $\lambda=1.24 \mu \mathrm{m}$ & $\lambda=1.64 \mu \mathrm{m}$ & $1 \lambda=2.13 \mu \mathrm{m}$ & $r_{g}$ & $\bar{\sigma}$ & $\overline{r_{\text {eff }}}$ & Comments \\
\hline 5 & $1.45-0.0035 \mathrm{i}$ & $1.45-0.0035 \mathrm{i}$ & $1.43-0.0035 \mathrm{i}$ & $1.43-0.0035 \mathrm{i}$ & 0.40 & 0.60 & 0.98 & Wet Sea salt type \\
\hline 6 & $1.45-0.0035 \mathrm{i}$ & $1.45-0.0035 i$ & $1.43-0.0035 \mathrm{i}$ & $1.43-0.0035 \mathrm{i}$ & 0.60 & 0.60 & 1.48 & Wet Sea salt type \\
\hline 7 & $1.45-0.0035 \mathrm{i}$ & $1.45-0.0035 \mathrm{i}$ & $1.43-0.0035 i$ & $1.43-0.0035 i$ & 0.80 & 0.60 & 1.98 & Wet Sea salt type \\
\hline 8 & $\begin{array}{l}1.53-0.003 \mathrm{i}(0.47) \\
1.53-0.001 \mathrm{i}(0.55) \\
1.53-0.000 \mathrm{i}(0.66) \\
1.53-0.000 \mathrm{i}(0.86)\end{array}$ & $1.46-0.000 \mathrm{i}$ & $1.46-0.001 i$ & $1.46-0.000 \mathrm{i}$ & 0.60 & 0.60 & 1.48 & Dust-like type \\
\hline 9 & $\begin{array}{l}1.53-0.003 \mathrm{i}(0.47) \\
1.53-0.001 \mathrm{i}(0.55) \\
1.53-0.000 \mathrm{i}(0.66) \\
1.53-0.000 \mathrm{i}(0.86)\end{array}$ & $1.46-0.000 \mathrm{i}$ & $1.46-0.001 i$ & $1.46-0.000 \mathrm{i}$ & 0.50 & 0.80 & 2.50 & Dust-like type \\
\hline
\end{tabular}

Levy et al. (2002) 
Table 3 Values of Assymetry parameter and Single Scattering Albedo for the 9 ocean models of Table 2.

\begin{tabular}{|c|c|c|c|c|c|c|c|}
\hline Model \# & $0.47 \mu \mathrm{m}$ & $0.55 \mu \mathrm{m}$ & $0.66 \mu \mathrm{m}$ & $0.87 \mu \mathrm{m}$ & $1.24 \mu \mathrm{m}$ & $1.61 \mu \mathrm{m}$ & $2.13 \mu \mathrm{m}$ \\
\hline \multicolumn{8}{|c|}{ Normalized Extinction Coeficients } \\
\hline 1 & 1.538 & 1.0 & 0.661 & 0.286 & 0.085 & 0.046 & 0.016 \\
\hline 2 & 1.300 & 1.0 & 0.764 & 0.427 & 0.169 & 0.081 & 0.030 \\
\hline 3 & 1.244 & 1.0 & 0.796 & 0.483 & 0.211 & 0.104 & 0.042 \\
\hline 4 & 1.188 & 1.0 & 0.836 & 0.549 & 0.269 & 0.140 & 0.060 \\
\hline 5 & 0.963 & 1.0 & 1.037 & 1.081 & 1.055 & 0.919 & 0.745 \\
\hline 6 & 0.980 & 1.0 & 1.034 & 1.100 & 1.177 & 1.166 & 1.081 \\
\hline 7 & 0.986 & 1.0 & 1.025 & 1.079 & 1.162 & 1.225 & 1.215 \\
\hline 8 & 0.977 & 1.0 & 1.023 & 1.086 & 1.185 & 1.192 & 1.124 \\
\hline 9 & 0.964 & 1.0 & 1.000 & 1.039 & 1.098 & 1.117 & 1.105 \\
\hline \multicolumn{8}{|c|}{ Assymetry parameter } \\
\hline 1 & 0.5755 & 0.5117 & 0.4478 & 0.3221 & 0.1773 & 0.1048 & 0.0622 \\
\hline 2 & 0.6832 & 0.6606 & 0.6357 & 0.5756 & 0.4677 & 0.3685 & 0.2635 \\
\hline 3 & 0.7354 & 0.7183 & 0.6991 & 0.6510 & 0.5590 & 0.4715 & 0.3711 \\
\hline 4 & 0.7513 & 0.7398 & 0.7260 & 0.6903 & 0.6179 & 0.5451 & 0.4566 \\
\hline 5 & 0.7450 & 0.7369 & 0.7328 & 0.7316 & 0.7330 & 0.7411 & 0.7282 \\
\hline 6 & 0.7770 & 0.7651 & 0.7503 & 0.7358 & 0.7314 & 0.7461 & 0.7446 \\
\hline 7 & 0.8035 & 0.7912 & 0.7738 & 0.7506 & 0.7335 & 0.7443 & 0.7461 \\
\hline 8 & 0.7534 & 0.7200 & 0.6979 & 0.6795 & 0.7129 & 0.7173 & 0.7190 \\
\hline 9 & 0.7801 & 0.7462 & 0.7234 & 0.7065 & 0.7220 & 0.7176 & 0.7151 \\
\hline \multicolumn{8}{|c|}{ Single scattering albedo } \\
\hline 1 & 0.9735 & 0.9683 & 0.9616 & 0.9406 & 0.8786 & 0.5390 & 0.4968 \\
\hline 2 & 0.9782 & 0.9772 & 0.9757 & 0.9704 & 0.9554 & 0.8158 & 0.8209 \\
\hline 3 & 0.9865 & 0.9864 & 0.9859 & 0.9838 & 0.9775 & 0.9211 & 0.9156 \\
\hline 4 & 0.9861 & 0.9865 & 0.9865 & 0.9855 & 0.9819 & 0.9401 & 0.9404 \\
\hline 5 & 0.9239 & 0.9358 & 0.9451 & 0.9589 & 0.9707 & 0.9753 & 0.9774 \\
\hline 6 & 0.8911 & 0.9026 & 0.9178 & 0.9377 & 0.9576 & 0.9676 & 0.9733 \\
\hline 7 & 0.8640 & 0.8770 & 0.8942 & 0.9175 & 0.9430 & 0.9577 & 0.9669 \\
\hline 8 & 0.9013 & 0.9674 & 1.0000 & 1.0000 & 1.0000 & 1.0000 & 1.0000 \\
\hline 9 & 0.8669 & 0.9530 & 1.0000 & 1.0000 & 1.0000 & 1.0000 & 1.0000 \\
\hline
\end{tabular}


Table 4. Contents of MODIS Aerosol Level 2 hdf file (MOD04): Time and geometric information.

\begin{tabular}{|l|l|l|}
\hline Name of product & Dimensidstatus \\
\hline Longitude & 2 D & diagnostic \\
\hline Latitude & 2 D & diagnostic \\
\hline Scan_Start_Time & 2 D & diagnostic \\
\hline Solar_Zenith & 2 D & diagnostic \\
\hline Solar_Azimuth & 2 D & diagnostic \\
\hline Sensor_Zenith & 2 D & diagnostic \\
\hline Sensor_Azimuth & 2 D & diagnostic \\
\hline Scattering_Angle & 2D & diagnostic \\
\hline Cloud_Mask_QA & 2 D & diagnostic \\
\hline
\end{tabular}

Dimension: 2 dimensional arrays of $204 \times 135$ are indicated. If the array is 3 dimensional, the values of the $3 \mathrm{rd}$ dimension are given. The $3 \mathrm{rd}$ dimension

Table 5. Contents of MODIS Aerosol Level 2 hdf file (MOD04): Global land and ocean products, at $550 \mathrm{~nm}$.

\begin{tabular}{|c|l|l|}
\hline Name of product & Dimension & status \\
\hline $\begin{array}{r}\text { Optical_Depth_Land_And } \\
\text { Ocean }\end{array}$ & 2 D & validated \\
\hline $\begin{array}{r}\text { Optical_Depth_Ratio_Small } \\
\text { Land_And_Ocean }\end{array}$ & 2 D & $\begin{array}{l}\text { Not yet } \\
\text { validated }\end{array}$ \\
\hline $\begin{array}{r}\text { Reflected_Flux_Land } \\
\text { And_Ocean }\end{array}$ & 2 D & derived \\
\hline
\end{tabular}


Table 6. Contents of MODIS Aerosol Level 2 hdf file (MOD04): Land products.

\begin{tabular}{|c|c|c|}
\hline Name of product & Dimension & Status \\
\hline Corrected_Optical_Depth & $\begin{array}{l}0.47,0.55 \\
0.66 \mu \mathrm{m}\end{array}$ & Validated \\
\hline \begin{tabular}{|r|} 
Optical_Depth_Ratio \\
Small_Land \\
\end{tabular} & $0.55 \mu \mathrm{m}$ & Not yet valid \\
\hline Mass_Concentration_Land & $2 \mathrm{D}$ & Derived \\
\hline Angstrom_Exponent_Land & $0.66 / 0.47$ & Not yet valid \\
\hline Reflected_Flux_Land & $\begin{array}{c}0.47,0.55 \\
0.66 \mu \mathrm{m} .6 \\
\end{array}$ & Derived \\
\hline Transmitted_Flux_Land & $\begin{array}{l}0.47,0.66 \\
\mu \mathrm{m}\end{array}$ & Derived \\
\hline Aerosol_Type_Land & $2 \mathrm{D}$ & Diagnostic \\
\hline $\begin{array}{c}\text { Continental_Optical_Depth } \\
\text { Land }\end{array}$ & $\begin{array}{l}0.47,0.66 \\
\mu \mathrm{m}\end{array}$ & Diagnostic \\
\hline Estimated_Uncertainty_Land & $\begin{array}{l}0.47,0.66 \\
\mu \mathrm{m}\end{array}$ & Diagnostic \\
\hline Mean_Reflectance_Land_All & $\begin{array}{l}0.47,0.66 \\
2.13 \mu \mathrm{m} \\
\end{array}$ & Diagnostic \\
\hline \begin{tabular}{|c|} 
Standard_Deviation \\
Reflectance_Land_All
\end{tabular} & \begin{tabular}{|c|}
$0.47,0.66$ \\
$2.13 \mu \mathrm{m}$
\end{tabular} & Diagnostic \\
\hline Cloud_Fraction_Land & $2 \mathrm{D}$ & Diagnostic \\
\hline $\begin{array}{r}\text { Number_Pixels_Percentile } \\
\text { LLand }\end{array}$ & $\begin{array}{l}0.47,0.66 \\
\mu \mathrm{m}\end{array}$ & Diagnostic \\
\hline Mean_Reflectance_Land & \begin{tabular}{|c}
$0.47,0.66$ \\
$0.87,2.13$ \\
$3.75 \mu \mathrm{m}$ \\
\end{tabular} & Diagnostic \\
\hline STD_Reflectance_Land & \begin{tabular}{|c|}
$0.47,0.66$ \\
$0.87,2.13$ \\
$3.75 \mu \mathrm{m}$
\end{tabular} & Diagnostic \\
\hline Quality_Assurance_Land & $\begin{array}{l}\text { See QA } \\
\text { plan }\end{array}$ & Diagnostic \\
\hline Path_Radiance_Land & $\begin{array}{l}0.47,0.66 \\
\mu \mathrm{m}\end{array}$ & Experimenta \\
\hline Error_Path_Radiance_Land & $\begin{array}{l}0.47,0.66 \\
\mu \mathrm{m}\end{array}$ & Diagnostic \\
\hline Critical_Reflectance_Land & $\begin{array}{l}0.47,0.66 \\
\mu \mathrm{m}\end{array}$ & Experimental \\
\hline $\begin{array}{r}\text { Error_Critical_Reflectance } \\
\text { Land }\end{array}$ & $\begin{array}{l}0.47,0.66 \\
\mu \mathrm{m}\end{array}$ & Diagnostic \\
\hline QualityWeight_Path_Radiance & $\begin{array}{l}0.47,0.66 \\
\mu \mathrm{m}\end{array}$ & Experimental \\
\hline $\begin{array}{r}\begin{array}{r}\text { QualityWeight_Critical } \\
\text { Reflectance_Land }\end{array} \\
\end{array}$ & $\begin{array}{l}0.47,0.66 \\
\mu \mathrm{m}\end{array}$ & Experimental \\
\hline $\begin{array}{c}\text { Quality_Assurance_Crit_Ref } \\
\text { _Land }\end{array}$ & $\begin{array}{c}0.47,0.66 \\
0.87,2.13, \\
3.75 \mu \mathrm{m}\end{array}$ & Diagnostic \\
\hline
\end{tabular}


Table 7. Contents of MODIS Aerosol Level 2 hdf file (MOD04): Ocean products.

\begin{tabular}{|c|c|c|}
\hline Name of product & Dimension & Status \\
\hline Effective_Optical_Depth_Average_Ocean & $\begin{array}{l}0.47,0.55,0.66,0.87 \\
1.24,1.63,2.13 \mu \mathrm{m}\end{array}$ & Validated \\
\hline Optical_Depth_Small_Average & $\begin{array}{l}0.47,0.55,0.66,0.87 \\
1.24,1.63,2.13 \mu \mathrm{m}\end{array}$ & Not yet validated \\
\hline Optical_Depth_Large_Average & $\begin{array}{l}0.47,0.55,0.66,0.87 \\
1.24,1.63,2.13 \mu \mathrm{m} \\
\end{array}$ & Not yet validated \\
\hline Effective_Radius_Ocean & Best, Average & Validated* \\
\hline Optical_Depth_Ratio_Small_Ocean_0.86micron & Best, Average & Not yet validated \\
\hline Mass_Concentration_Ocean & Best, Average & Derived \\
\hline Cloud_Condensation_Nuclei_Ocean & Best, Average & Derived \\
\hline Angstrom Exponent_1_Ocean & $0.55 / 0.87$ & Not yet validated \\
\hline Angstrom_Exponent_2_Ocean & $0.87 / 2.13$ & Not yet validated \\
\hline Reflected_Flux_Average_Ocean & $\begin{array}{l}0.47,0.55,0.66,0.87 \\
1.24,1.63,2.13 \mu \mathrm{m} \\
\end{array}$ & Derived \\
\hline Transmitted_Flux_Average_Ocean & $\begin{array}{l}0.47,0.55,0.66,0.87 \\
1.24,1.63,2.13 \mu \mathrm{m}\end{array}$ & Derived \\
\hline Asymmetry_Factor_Average_Ocean & $\begin{array}{l}0.47,0.55,0.66,0.87 \\
1.24,1.63,2.13 \mu \mathrm{m} \\
\end{array}$ & Derived \\
\hline Backscattering_Ratio_Average_Ocean & $\begin{array}{l}0.47,0.55,0.66,0.87 \\
1.24,1.63,2.13 \mu \mathrm{m} \\
\end{array}$ & Derived \\
\hline Solution_Index_Ocean_Small & Best, Average & Diagnostic \\
\hline Solution_Index_Ocean_Large & Best, Average & Diagnostic \\
\hline Least_Squares_Error_Ocean & Best, Average & Diagnostic \\
\hline Optical_Depth_by_models_ocean & 9 models & Diagnostic \\
\hline Effective_Optical_Depth_Best_Ocean & $\begin{array}{l}0.47,0.55,0.66,0.87 \\
1.24,1.63,2.13 \mu \mathrm{m} \\
\end{array}$ & Diagnostic \\
\hline Optical_Depth_Small_Best & $\begin{array}{l}0.47,0.55,0.66,0.87 \\
1.24,1.63,2.13 \mu \mathrm{m} \\
\end{array}$ & Diagnostic \\
\hline Optical_Depth_Large_Best & $\begin{array}{l}0.47,0.55,0.66,0.87 \\
1.24,1.63,2.13 \mu \mathrm{m} \\
\end{array}$ & Diagnostic \\
\hline Reflected_Flux_Best_Ocean & $\begin{array}{l}0.47,0.55,0.66,0.87 \\
1.24,1.63,2.13 \mu \mathrm{m}\end{array}$ & Diagnostic \\
\hline Transmitted_Flux_Best_Ocean & $\begin{array}{l}0.47,0.55,0.66,0.87 \\
1.24,1.63,2.13 \mu \mathrm{m}\end{array}$ & Diagnostic \\
\hline Asymmetry_Factor_Best_Ocean & $\begin{array}{l}0.47,0.55,0.66,0.87 \\
1.24,1.63,2.13 \mu \mathrm{m} \\
\end{array}$ & Diagnostic \\
\hline Backscattering_Ratio_Best_Ocean & \begin{tabular}{|l|}
$0.47,0.55,0.66,0.87$ \\
$1.24,1.63,2.13 \mu \mathrm{m}$ \\
\end{tabular} & Diagnostic \\
\hline Cloud_Fraction_Ocean & 2 dimensional & Diagnostic \\
\hline Number_Pixels_Used_Ocean & 2 dimensional & Diagnostic \\
\hline Mean_Reflectance_Ocean & $\begin{array}{l}0.47,0.55,0.66,0.87 \\
1.24,1.63,2.13 \mu \mathrm{m} \\
\end{array}$ & Diagnostic \\
\hline STD_Reflectance_Ocean & $\begin{array}{l}0.47,0.55,0.66,0.87 \\
1.24,1.63,2.13 \mu \mathrm{m} \\
\end{array}$ & Diagnostic \\
\hline Quality_Assurance_Ocean & See QA plan & Diagnostic \\
\hline
\end{tabular}


Table 8. Number of retrievals $(\mathrm{N})$, percentage of retrievals (\%) falling within expected uncertainty for each derived wavelength, average optical thickness from AERONET $\left(\tau^{0.55}\right)$ and percent difference between MODIS and AERONET at $0.55 \mu \mathrm{m}$ (Diff) for the global data set and for each region, land and ocean separately.

\begin{tabular}{|c|c|c|c|c|c|c|c|}
\hline Region & $\mathrm{N}$ & $\% 0.47$ & $\% 0.55$ & $\% 0.66$ & $\% 0.87$ & $\tau^{0.55}$ & Diff \\
\hline All land & 5906 & 61 & 68 & 71 & & 0.18 & 41 \\
\hline China_land & 205 & 71 & 75 & 76 & & 0.28 & 17 \\
\hline India_land & 70 & 70 & 90 & 79 & & 0.46 & -2 \\
\hline Mediterranean_land & 781 & 65 & 67 & 66 & & 0.20 & 32 \\
\hline Alaska/Canada_land & 178 & 49 & 57 & 67 & & 0.10 & 122 \\
\hline South Africa_land & 347 & 79 & 86 & 84 & & 0.19 & -10 \\
\hline South America_land & 762 & 63 & 72 & 75 & & 0.18 & 21 \\
\hline West US_land & 901 & 56 & 61 & 63 & & 0.14 & 53 \\
\hline East US _land & 1385 & 55 & 64 & 68 & & 0.17 & 54 \\
\hline East Europe_land & 192 & 79 & 83 & 72 & & 0.24 & -10 \\
\hline West Europe_land & 793 & 66 & 72 & 77 & & 0.17 & 48 \\
\hline
\end{tabular}

\begin{tabular}{|c|c|c|c|c|c|c|c|}
\hline Region & $\mathrm{N}$ & $\% 0.47$ & $\% 0.55$ & $\% 0.66$ & $\% 0.87$ & $\tau^{0.55}$ & $\operatorname{Diff}(\%)$ \\
\hline All ocean & 2052 & & 62 & 66 & 70 & 0.18 & 1 \\
\hline Indian_ocean & 47 & & 64 & 77 & 77 & 0.16 & 7 \\
\hline Asian Pacific_ocean & 57 & & 56 & 53 & 60 & 0.21 & 13 \\
\hline Pacific Island ocean & 163 & & 70 & 74 & 79 & 0.08 & -6 \\
\hline West Medit_ocean & 334 & & 52 & 62 & 68 & 0.21 & -6 \\
\hline East Medit_ocean & 205 & & 57 & 63 & 71 & 0.23 & -7 \\
\hline Sahara $n$ ocean & 184 & & 58 & 56 & 51 & 0.31 & 1 \\
\hline Atlantic Isles_ocean & 146 & & 64 & 71 & 71 & 0.13 & 8 \\
\hline Australia_ocean & 70 & & 83 & 81 & 83 & 0.05 & 2 \\
\hline North Europe_ocean & 150 & & 65 & 72 & 81 & 0.16 & -8 \\
\hline Caribbean_ocean & 242 & & 62 & 67 & 68 & 0.14 & 20 \\
\hline East Pacific_ocean & 160 & & 52 & 61 & 69 & 0.18 & -6 \\
\hline US Atlantic_ocean & 288 & & 72 & 68 & 70 & 0.15 & 7 \\
\hline
\end{tabular}


MODIS Over Land Algorithm

All procedures applied to individual boxes of $20 \times 20$ pixels at $500 \mathrm{~m}$ resolution ( $10 \mathrm{~km}$ at nadir)

Identify and mask all water, cloudy and snow/ice pixels.

Separate all pixels that are outside of $0.01<\rho_{2.13} \leq 0.25$

Discard brightest $50 \%$ and darkest $20 \%$ of pixels defined with $\rho_{0.66}$

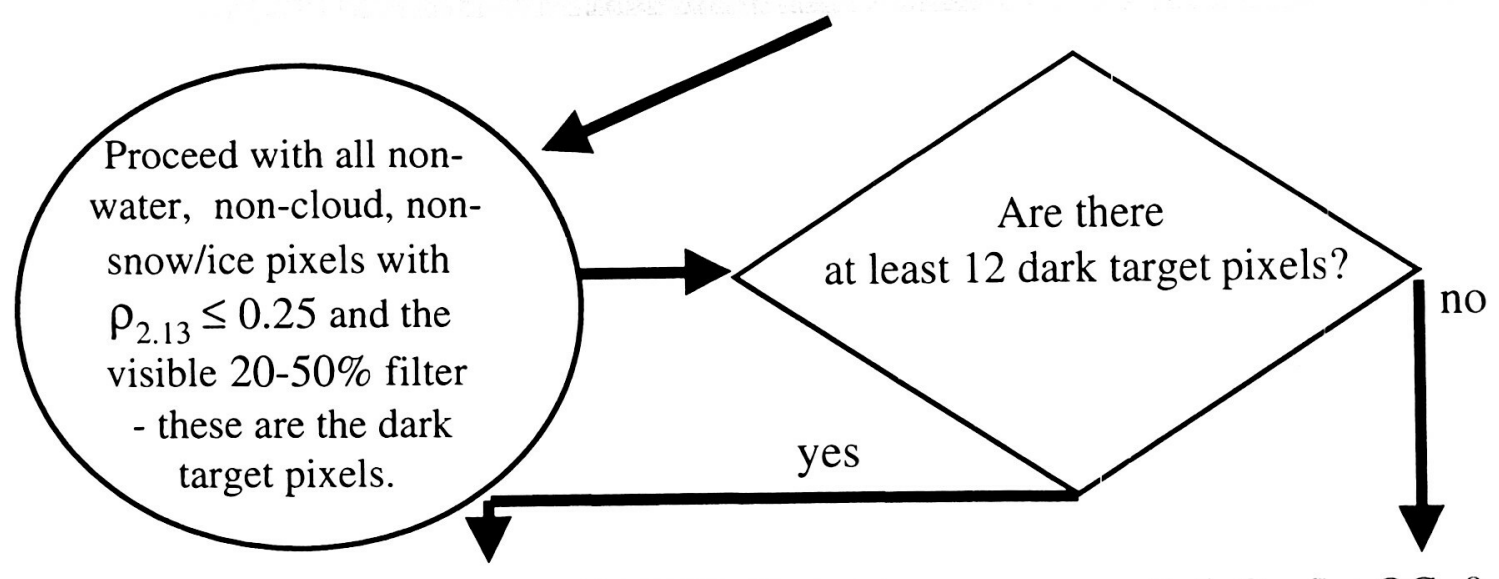

Path A - Set QC=3

For all identified 'dark' pixels,

Calculate mean $\rho_{0.47}, \rho_{0.66}$

$\rho_{\mathrm{S}}{ }^{0.47}=0.25 \rho^{2.13} ; \rho_{\mathrm{s}}{ }^{0.66}=0.50 \rho^{2.13}$

Path B - Set QC $=0$

Now collect pixels with $\rho_{2.13}>0.25$

previously set aside. Count number of pixels $(\mathrm{N})$ with

$0.01 \leq \rho_{2.13} \leq 0.25 \mathrm{f}\left(\mu, \mu_{\mathrm{o}}\right)$

Continental model LUT $\rightarrow \tau_{0.47}$ and $\tau_{0.66}$

Calculate path radiance $\left(\rho_{o}\right)$ at 0.47 and 0.66

Spectral dependence of path radiance distinguishes dust from non-dust.
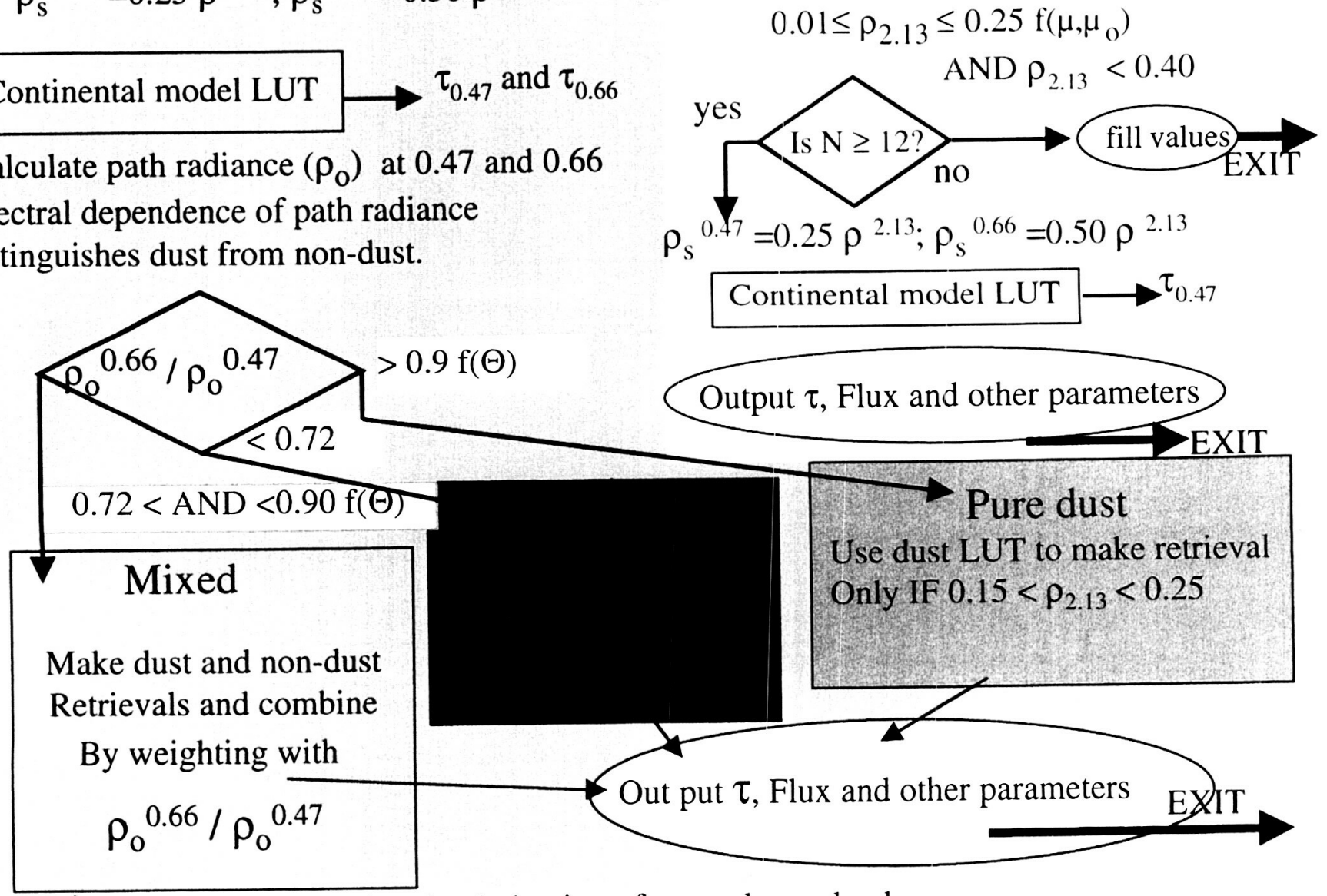

Figure 1 Flowchart illustrating the derivation of aerosol over land. 


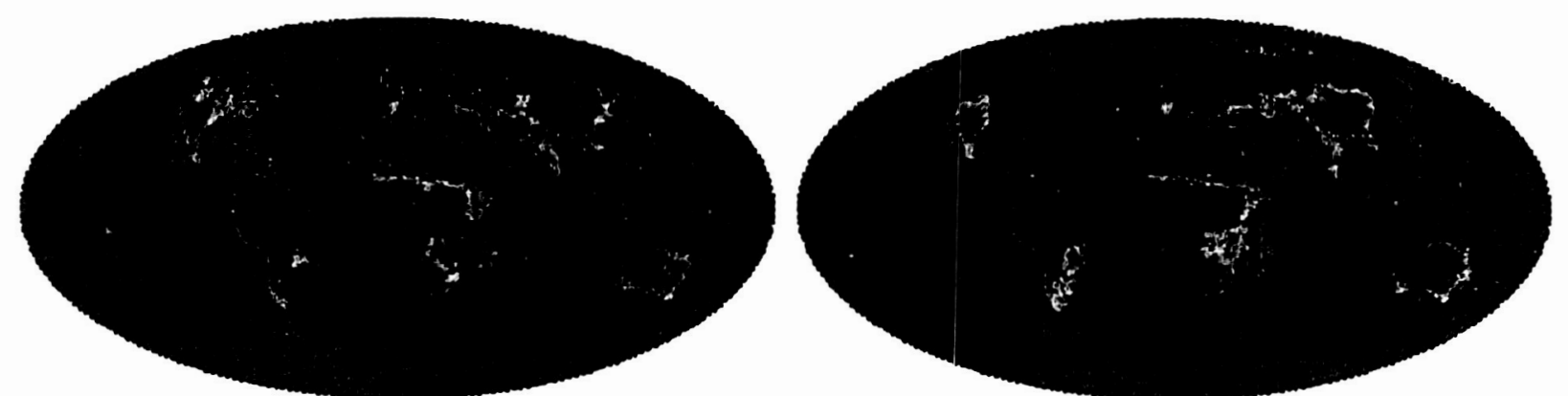

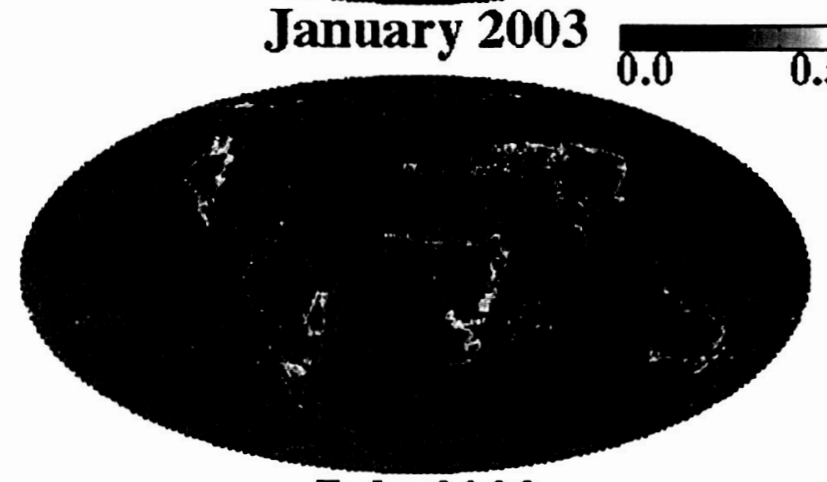

July 2002
April 2003

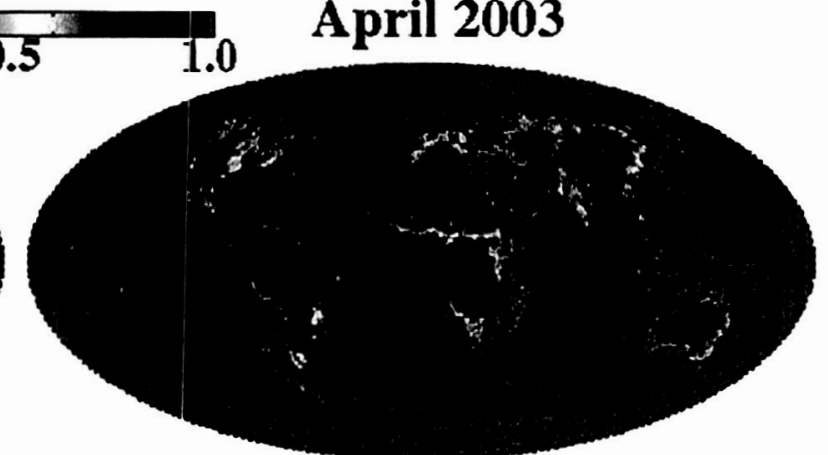

October 2002

Figure 2. Monthly mean plots of fraction of total aerosol optical thickness attributed to 'nondust' or fine mode aerosol over land. Fraction 1.0 indicates all fine mode. Fraction of 0.0 indicates all coarse mode. 


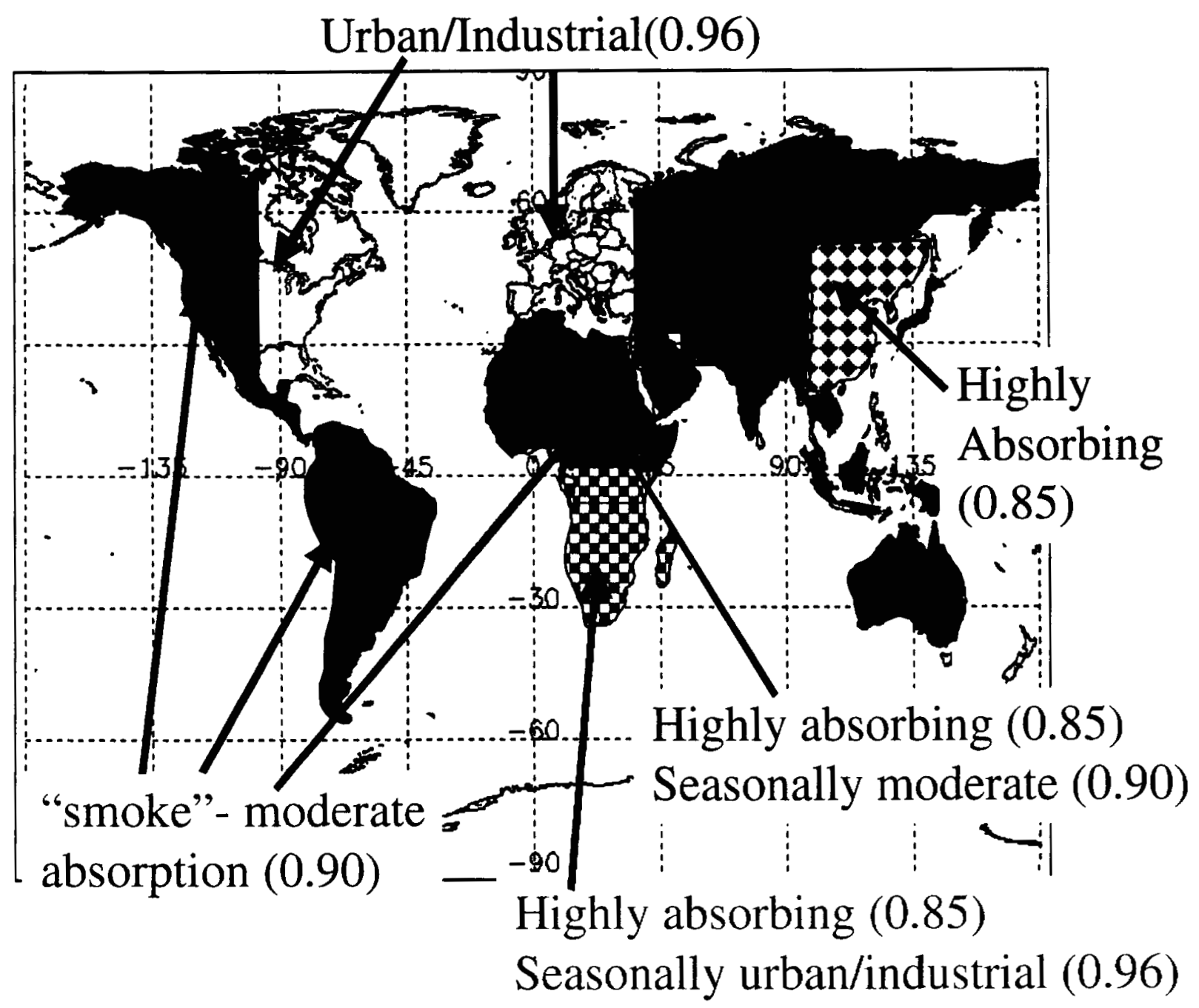

Figure 3. Distribution of the non-dust models used in the derivation of aerosol over land. Single scattering albedo values given in parentheses. Uncolored regions use the urban/industrial aerosol model. Solid black regions use the moderate absorption aerosol model all year. Large checkerboard pattern in east Asia denotes a region of strong absorption aerosol model all year. Africa is divided by region and season. North of the equator, during the burning season (November-May) the strong absorption aerosol model is used, while the moderate absorption model is used the remainder of the year. South of the equator, the burning season shifts to JuneOctober when the strong absorption model is used, while in the remainder of the year the algorithm uses the urban/industrial model. 


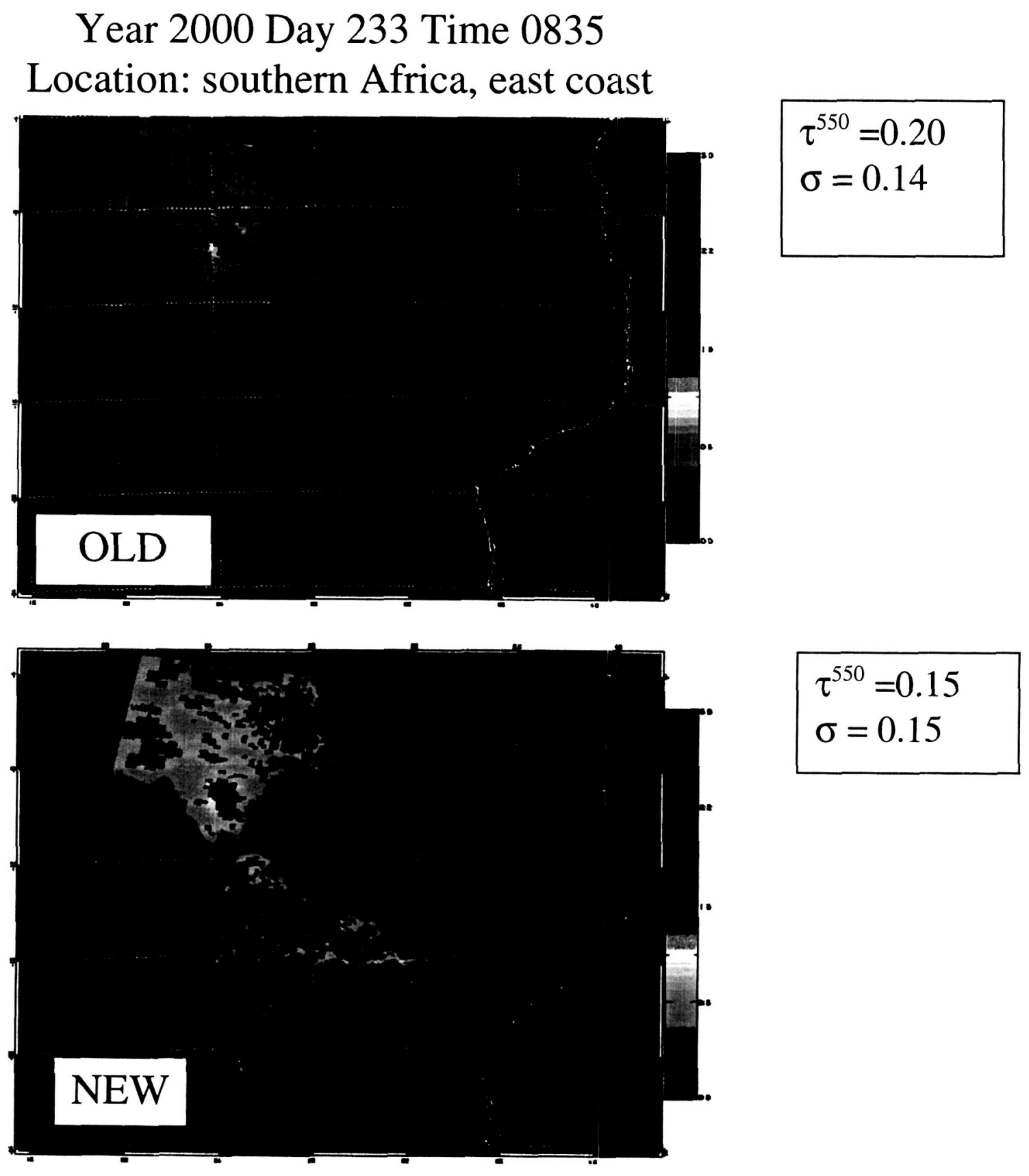

Figure 4. MODIS-derived aerosol optical thickness at $0.55 \mu \mathrm{m}$ for an image of the east coast of southern Africa. Top panel uses the traditional dark target method described by Path A in Figure 2. The bottom panel shows the results after extending the retrieval to brighter surfaces as described by Path B of Figure 2. By extending to brighter surfaces the number of retrievals over land in this image increases from 7060 to 17,849 . 


\section{MODIS Aerosol Over Ocean Algorithm}

All procedures applied to individual boxes of $20 \times 20$ pixels at $500 \mathrm{~m}$ resolution $(10 \mathrm{~km}$ at nadir $)$

\section{Entire box clear of land pixels according to MOD35 $1 \mathrm{~km}$ mask? No?} Go to Land Algorithm

Yyes? $\longrightarrow$ Continue masking pixel by pixel

(1) Spatial variability: stdev of $\rho^{0.55}$ calculate from $3 \times 3$ centered on pixel $>0.0025$ then all 9 pixels labeled 'cloudy'.

(2) dust call back: if $\rho^{0.47} / \rho^{0.66}<0.75$, then dust, use even if variability is high.

(3) if $\varrho^{0.47} \geq 0.40$ then 'cloudy'

(4) IR tests: if any of 3 specific MOD35 tests indicate 'cloudy', then 'cloudy'

(5) 1.38 cirnus tests: cloudy if $\rho^{1.38} / \rho^{1.24}>0.3$ OR if $0.01 \leq \rho^{1.38 / \rho^{1.24} \leq 0.30}$

$$
\text { AND } \rho 1.38>0.03
$$

but, if $0.10 \leq \rho^{1.38} / \rho^{1.24} \leq 0.30$

AND $0.01 \leq \rho^{1.38} \leq 0.03$ then

'not cloudy' but $\mathrm{QC}=0$

(6) sediment mask:
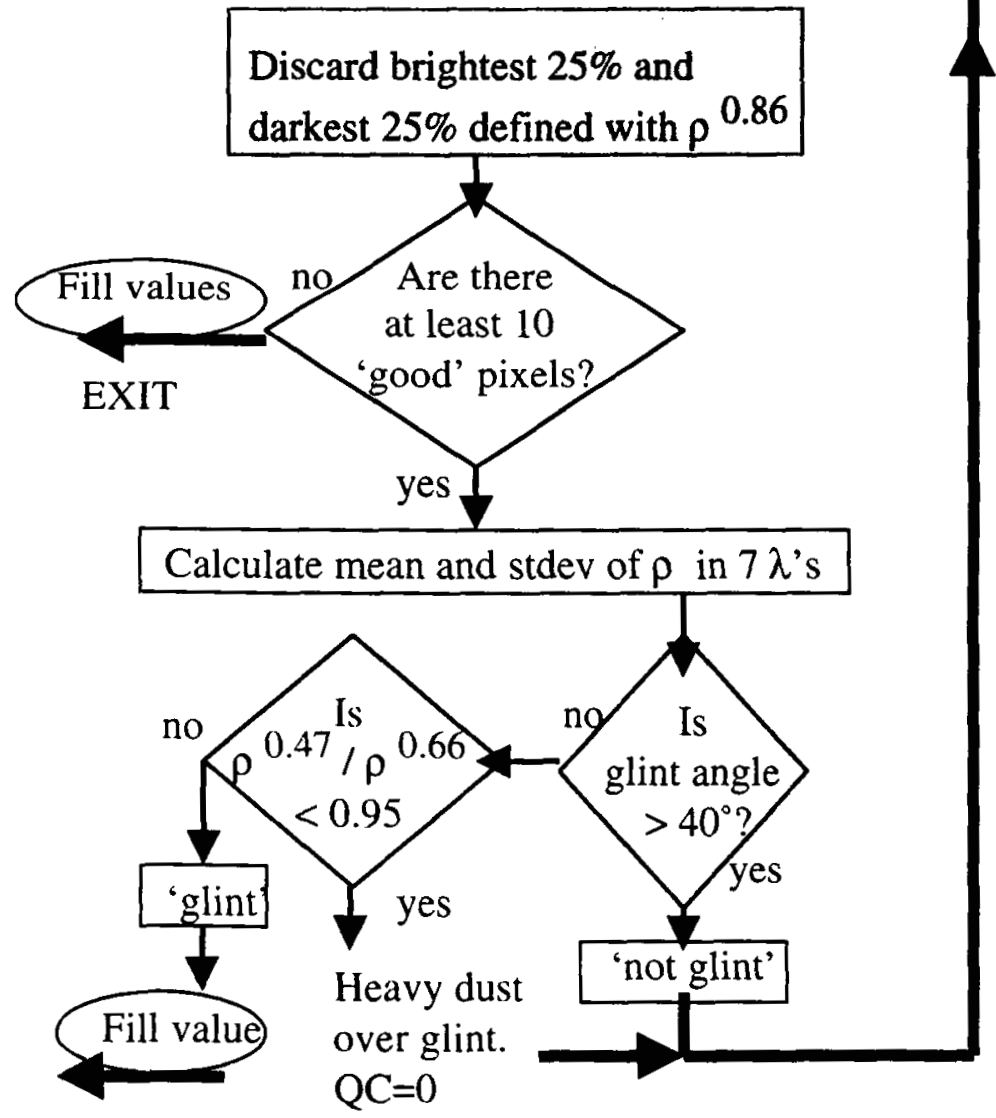

EXIT

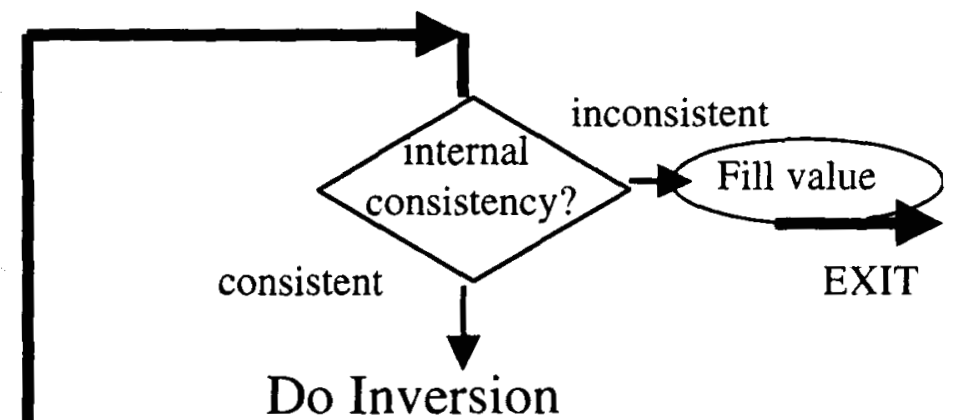

For all 20 combinations

of 1 fine mode and 1 coarse mode,

Find $\eta$ and $\tau$ such that

$\rho_{\mathrm{m}}^{\lambda}-\rho_{\mathrm{tot}} \lambda^{\lambda}$ is minimum over all $\lambda$ 's where $\rho_{\mathrm{m}} \lambda$ is MODIS measured reflectance and $\rho_{\text {tot }}{ }^{\lambda}=\eta \rho_{\mathrm{f}}^{\lambda}+(1-\eta) \rho_{\mathrm{c}}{ }^{\lambda}$ from the LUT.

Choose which of the 20 combinations

has least error $(\varepsilon)$

Note in minimizing $\varepsilon$, wavelengths are

weighted for information content and QC.

Chosen LUTs $\longrightarrow \tau$, Flux in $7 \lambda$ 's, r_eff etc. Best solution is least error.

Average solution is either:

(a) average of all solutions where $\varepsilon<3 \%$

(b) if no $\varepsilon<3 \%$, then average of best 3

\section{Final Checking}

If $\tau \leq 5.0$ Output $\tau$, flux in $7 \lambda$ 's, r_eff etc.

Except For Dust when $\tau<0.7$
Fill value
EXIT

EXIT

If $\tau>5.0$ For Dust, set $\tau=5.0$

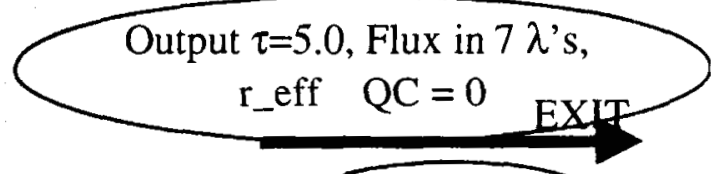

For Not Dust Fill value 


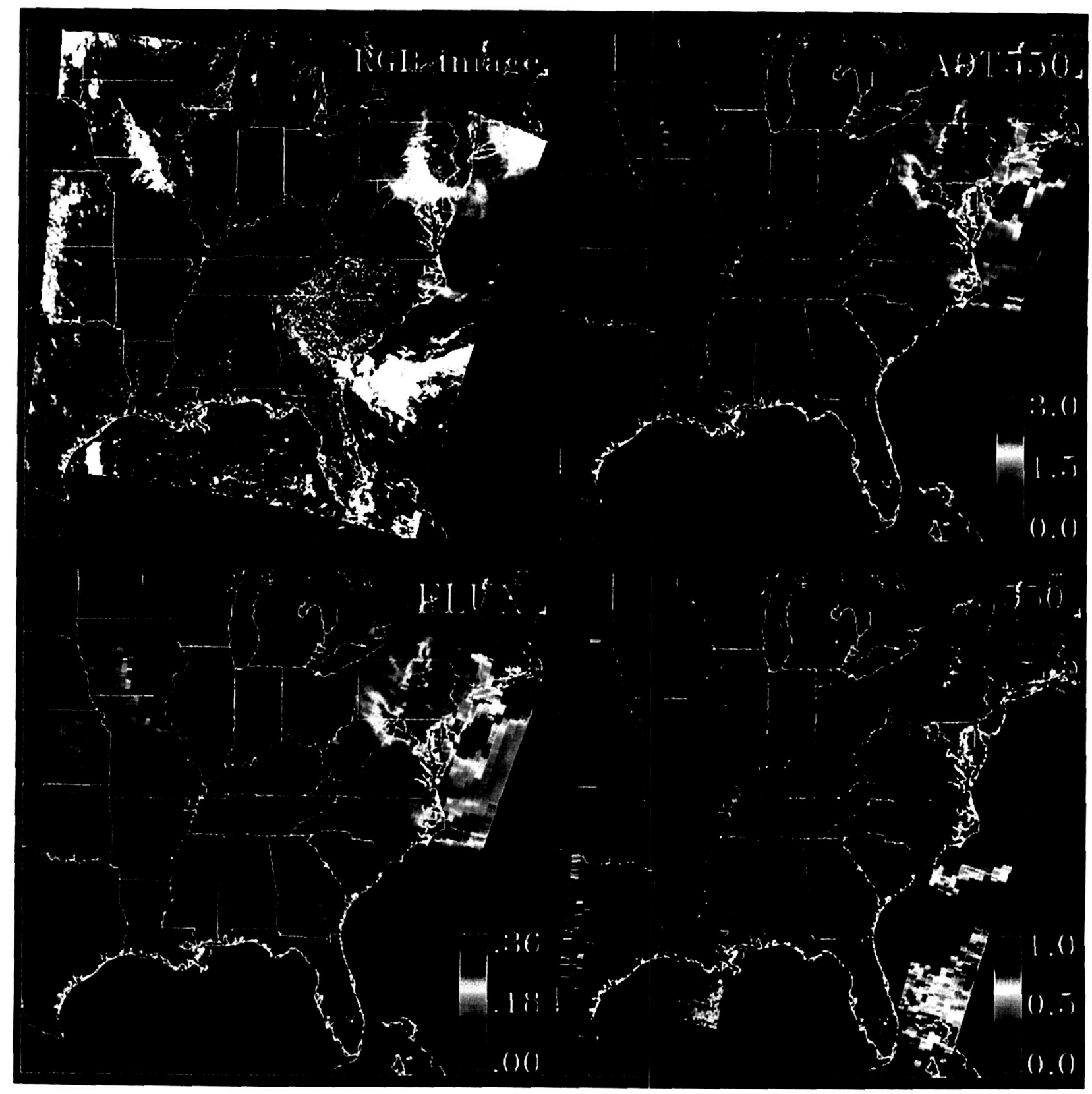

Figure 6. Examples of MODIS aerosol products at the Level 2 stage (MOD04). The data represent a 5-minute granule collected on July 7, 2002 from 1835-1840 UTC. The upper left panel is a true color image created from Level $1 \mathrm{~b}$ reflectances. The upper right panel is aerosol optical thickness at $550 \mathrm{~nm}$, The lower left panel is reflected flux at $550 \mathrm{~nm}$. The lower right panel is fraction of fine mode. 


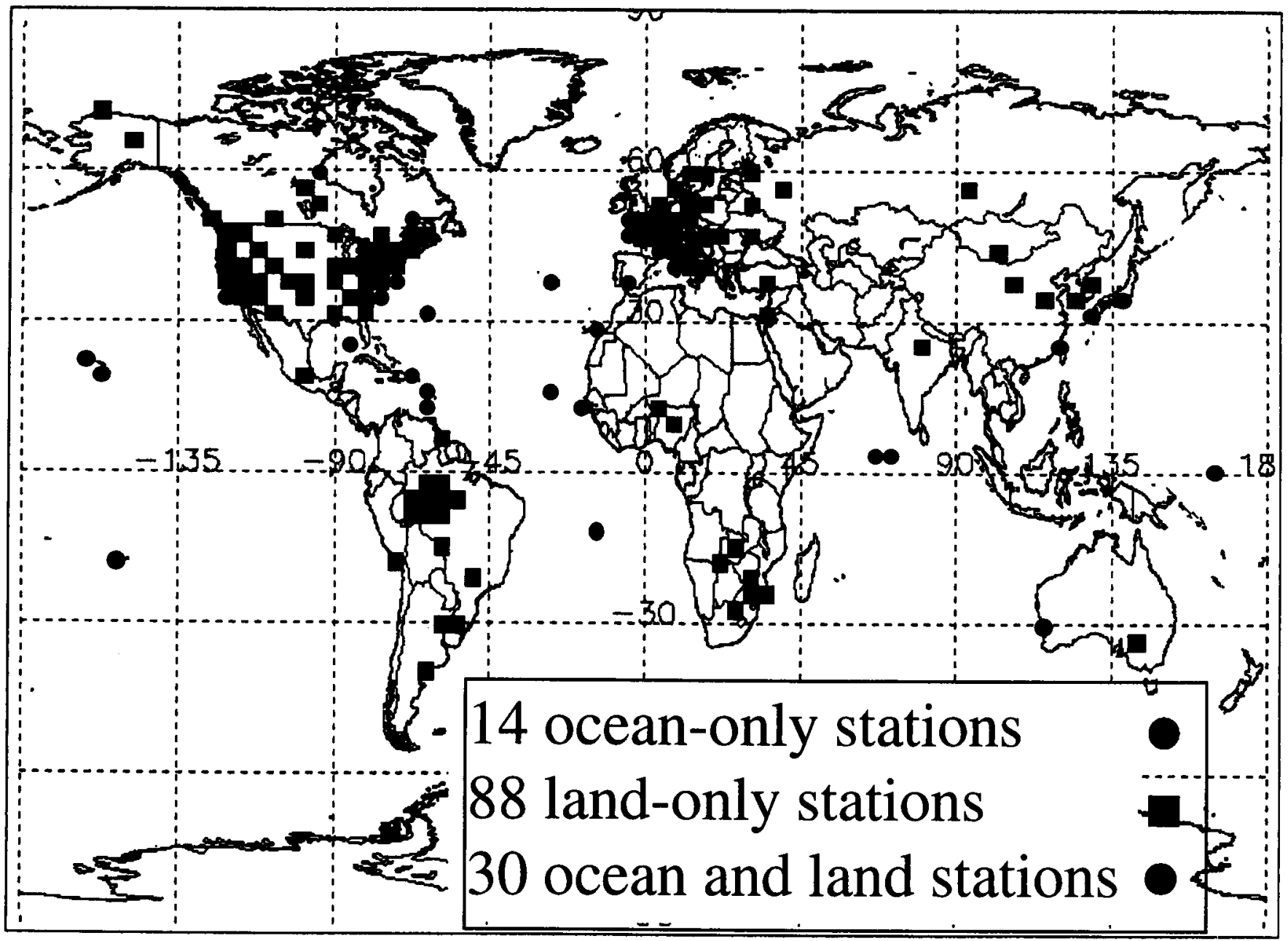

Figure 7. The distribution of the 132 AERONET stations used to validate MODIS land and ocean aerosol retrieval algorithms. 

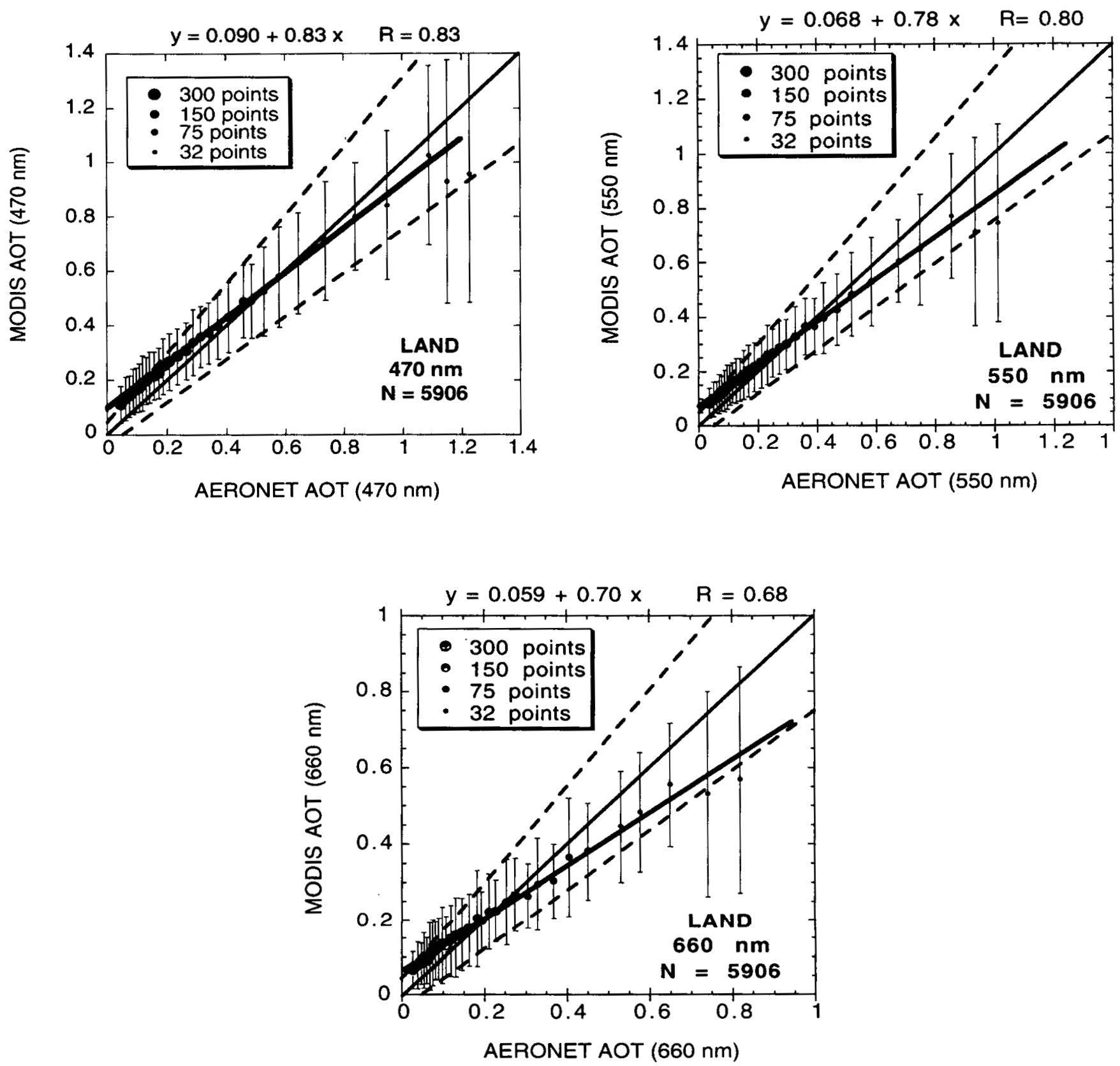

Figure 8. MODIS aerosol optical thickness retrievals over land at $470 \mathrm{~nm}$ (blue), $550 \mathrm{~nm}$ (green ) and $660 \mathrm{~nm}$ (red) as a function of AERONET observations co-located in space and time. The data were sorted according to AERONET aerosol optical thickness and averaged for every 300 points. At higher optical thickness where the data beome sparser, fewer points are used in the average, as indicated. The standard deviation in each bin is shown by error bars. The regression equations given at the top of each plot were calculated from the full scatter plots before binning. The solid black line is th 1:1 line and the dashed lines denote the expected uncertainty calculated from pre-launch analysis. 

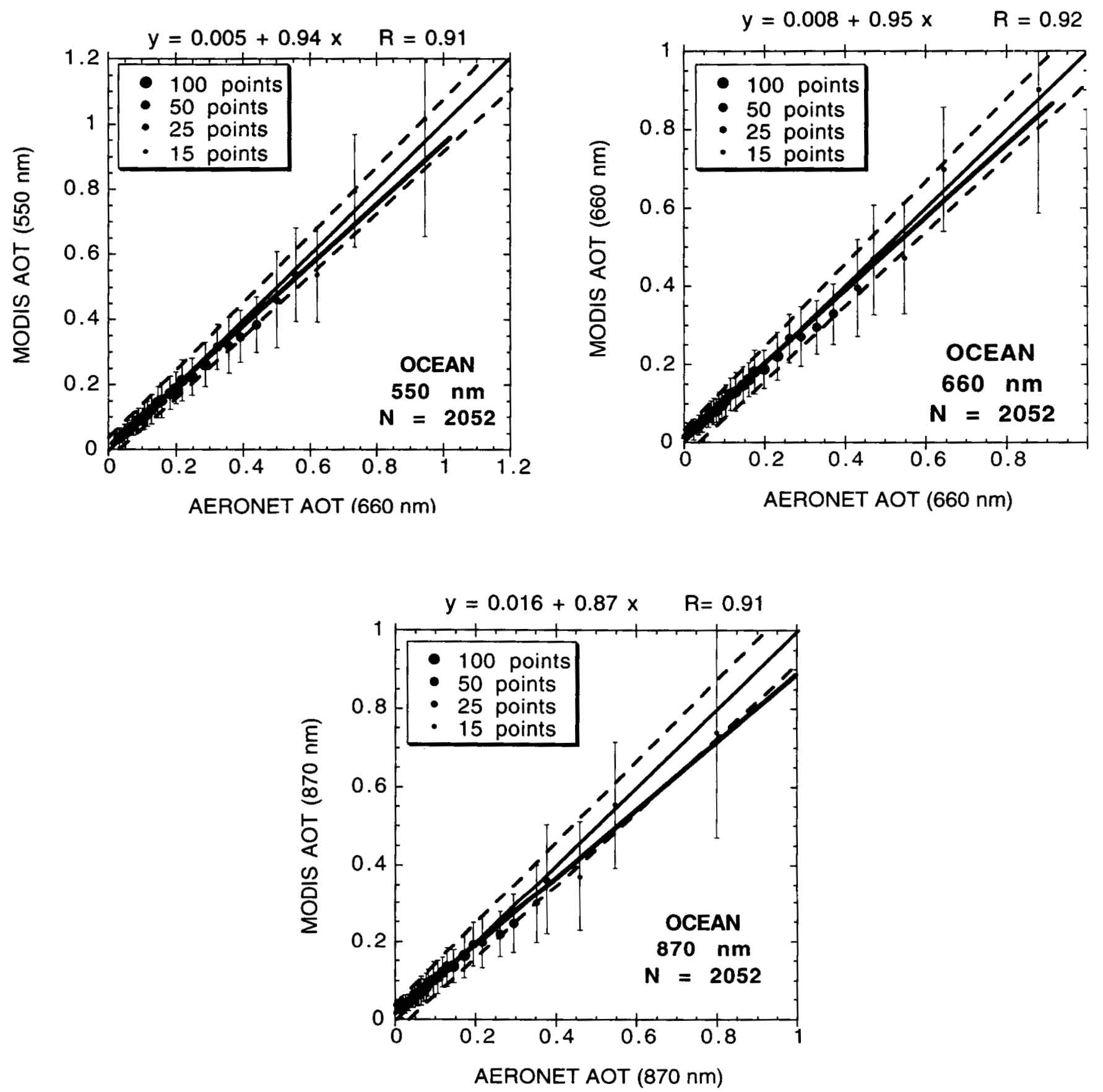

Figure 9. MODIS aerosol optical thickness retrievals over ocean at $550 \mathrm{~nm}$ (green ) and $660 \mathrm{~nm}$ (red) and $870 \mathrm{~nm}$ (black) as a function of AERONET observations co-located in space and time. The data were sorted according to AERONET aerosol optical thickness and averaged for every 100 points. At higher optical thickness where the data become sparser, fewer points are used in the average, as indicated. The standard deviation in each bin is shown by error bars. The regression equations given at the top of each plot were calculated from the full scatter plots before binning. The solid black line is the 1:1 line and the dashed lines denote the expected uncertainty calculated from pre-launch analysis. 


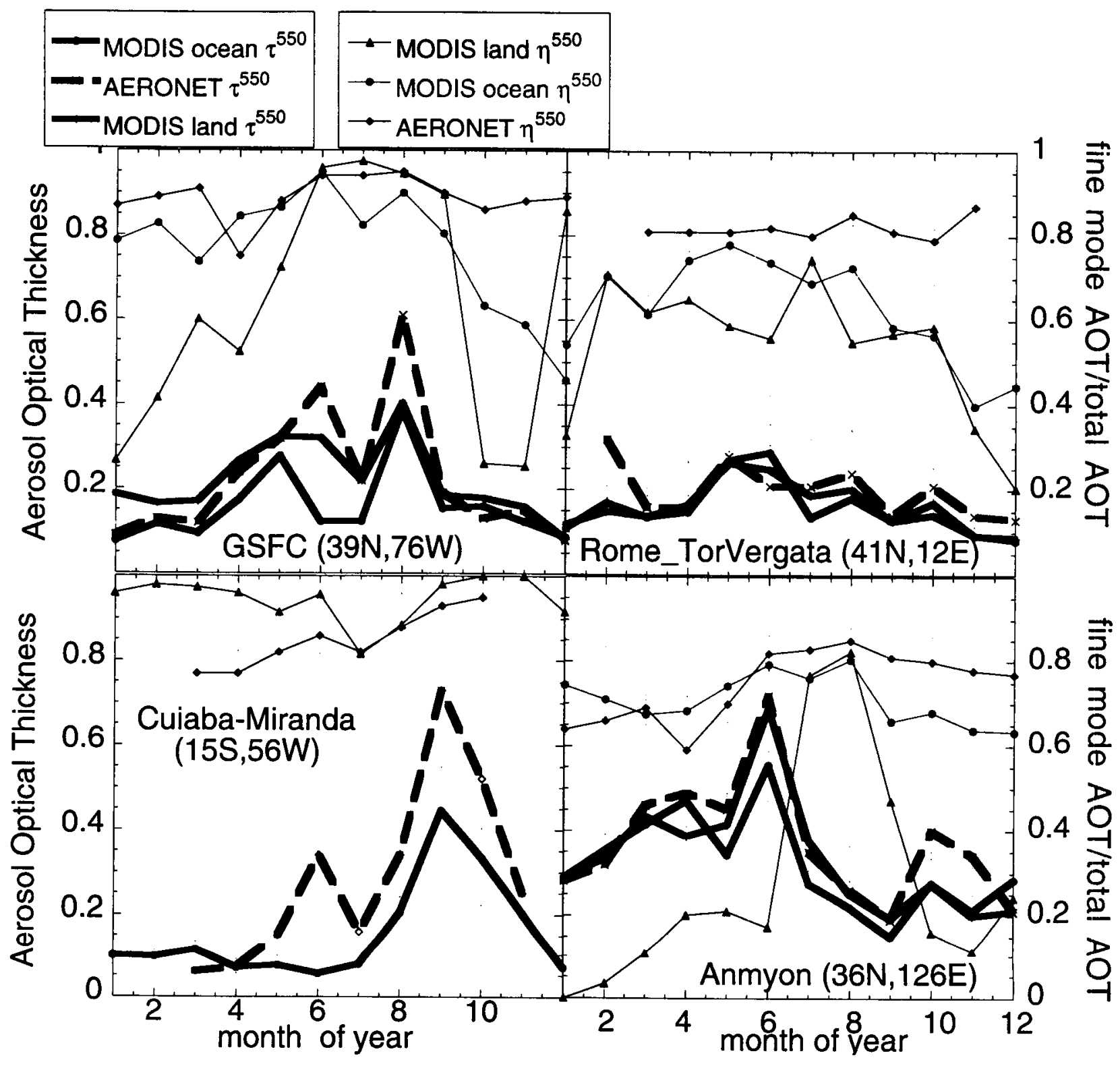

Figure 10. Monthly mean aerosol optical thickness at $0.55 \mu \mathrm{m}$ (heavy lines and left hand axes) and fraction of optical thickness contributed by fine mode at $0.55 \mu \mathrm{m}$ ( thin lines and right hand axes) for the year 2001. Blue denotes MODIS ocean retrievals. Red denotes MODIS land retrievals, and black denotes AERONET. Four land stations are shown. The MODIS values are calculated from Level 3 daily statistics and represent a 3 degree latitude by 3 degree longitude box centered on the AERONET station. 


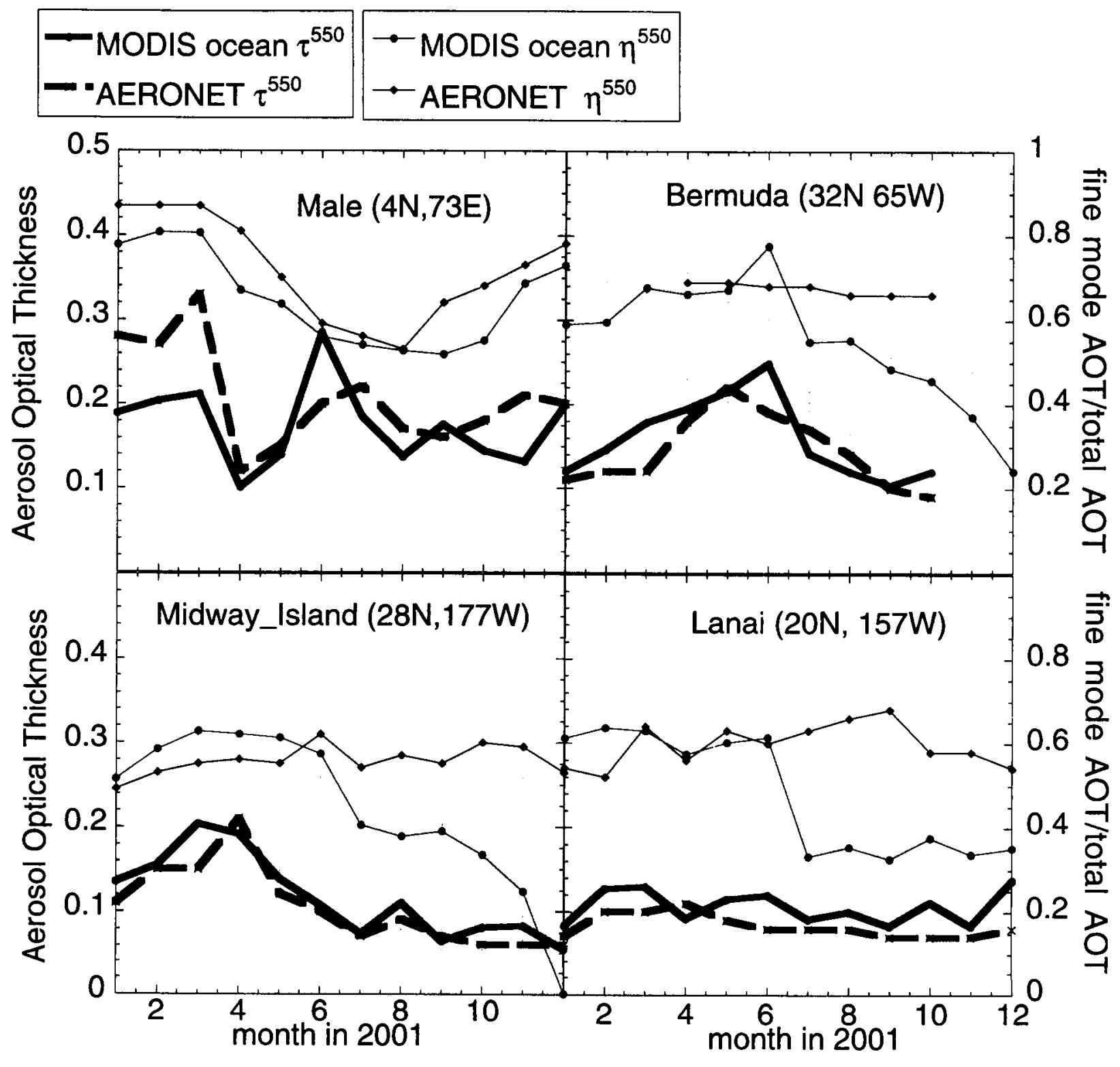

Figure 10b. 


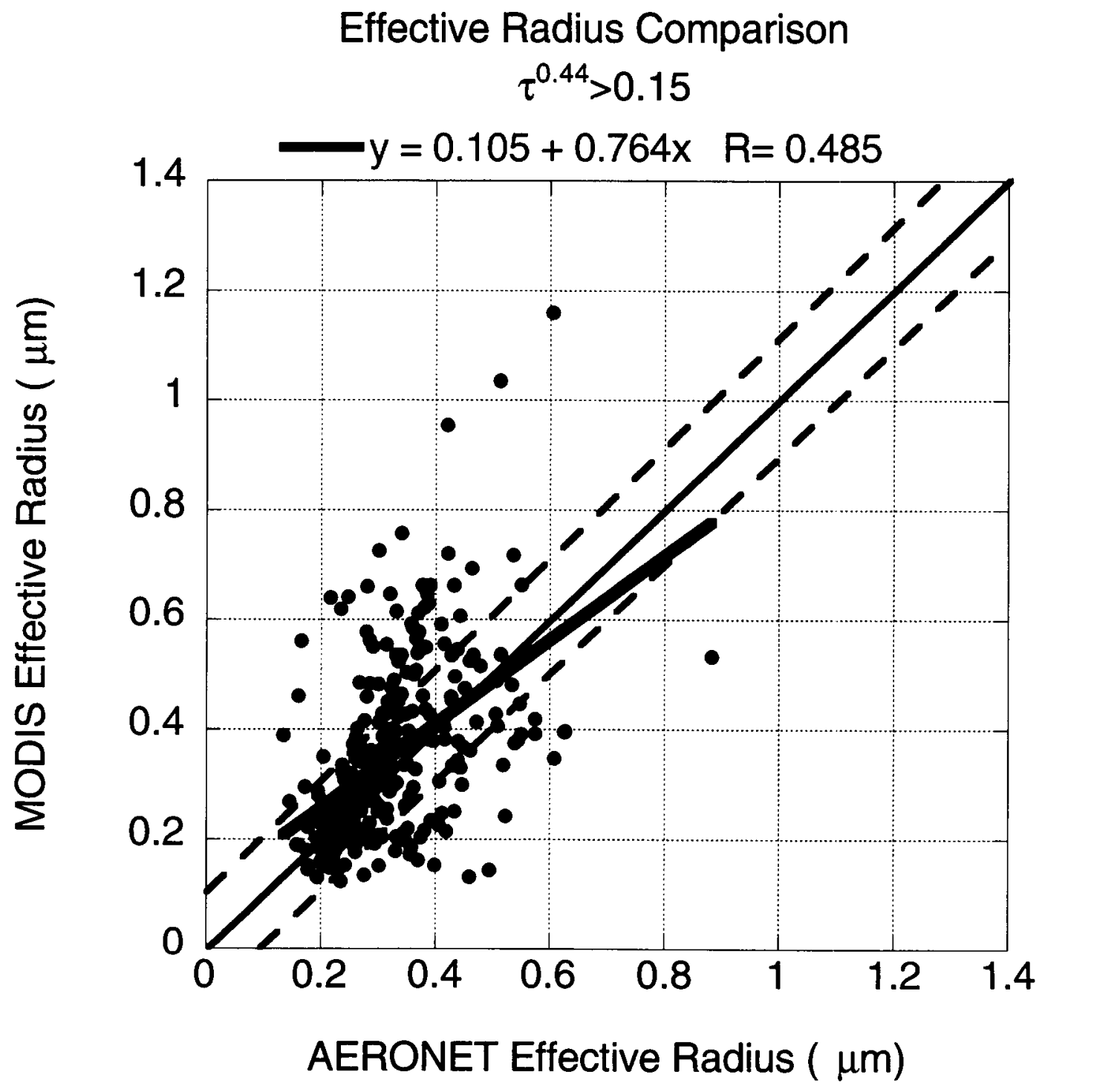

Figure 11. MODIS retrieved aerosol particle effective radius over ocean plotted against AERONET retrievals of the same parameter. Only points with AERONET $\tau^{0.44}>0.15$ are plotted. AERONET values are daily averages for the date of the MODIS overpass. The blue line represents the linear regression through the points. The solid black line is the 1:1 line and the dashed lines represent $\pm 0.10 \mu \mathrm{m}$. 271 co-located points are shown. $62 \%$ of these points fall within the dashed lines. 
Red $=$ fine

Green $=$ coarse

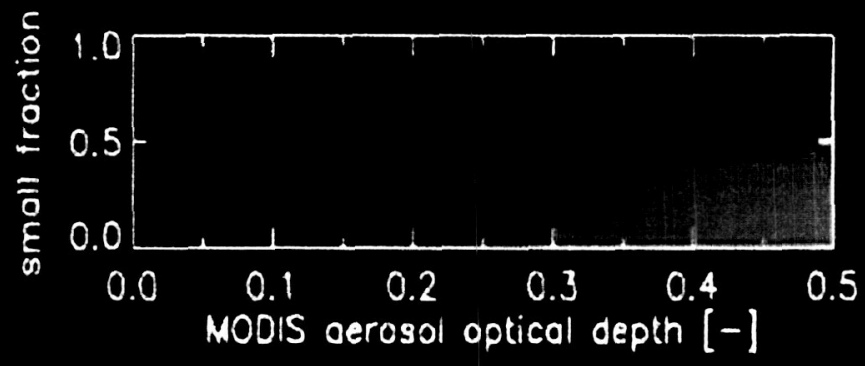

Figure 12. MODIS aerosol optical thickness at $550 \mathrm{~nm}$, representing global aerosol distribution on August 12, 2001. The two dimensional color bar describes both magnitude of optical thickness (along bottom axis) and fraction of optical thickness contributed by smaller fine mode particles (along vertical axis). Blue indicates low aerosol loading. Red indicates heavy loading of small particles such as pollution and smoke. The greener tones indicate a greater percentage of large particles such as desert dust and sea salt. The image was created from the MODIS daily $10-\mathrm{km}$ resolution data after smoothing the raw data with Gaussian filters applied both in the temporal and spatial domains. 